
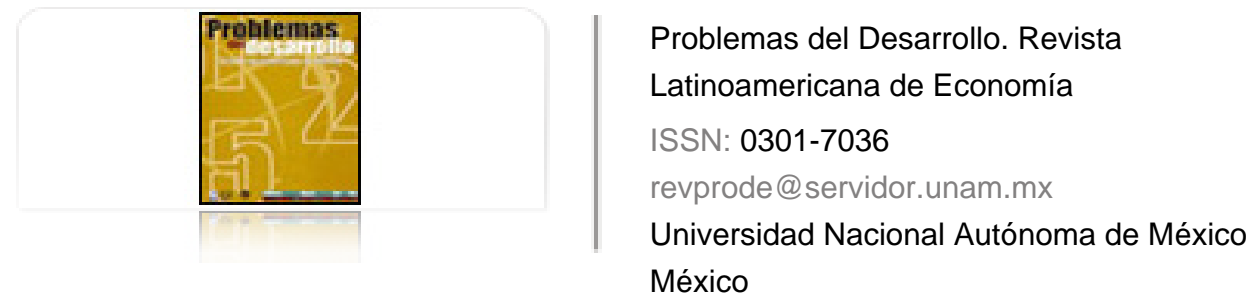

Ordoñez, Sergio

LA CRISIS GLOBAL ACTUAL Y EL SECTOR ELECTRÓNICO-INFORMÁTICO

Problemas del Desarrollo. Revista Latinoamericana de Economía, vol. 40, núm. 158, julio-septiembre, 2009, pp. 55-90

Universidad Nacional Autónoma de México

Distrito Federal, México

Disponible en: http://www.redalyc.org/articulo.oa?id=11820200003

Cómo citar el artículo

- Número completo

- Más información del artículo

Página de la revista en redalyc.org

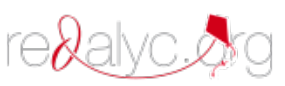

Sistema de Información Científica

Red de Revistas Científicas de América Latina, el Caribe, España y Portugal Proyecto académico sin fines de lucro, desarrollado bajo la iniciativa de acceso abierto 


\title{
LA CRISIS GLOBAL ACTUAL Y EL SECTOR ELECTRÓNICO-INFORMÁTICO
}

\author{
Sergio Ordoñez*
}

Fecha de recepción: 19 de mayo de 2009. Fecha de aceptación: 28 de julio de 2009.

\section{Resumen}

Los efectos de la crisis financiero-productiva global sobre el SE-I mundial han sido moderados: este sector se encuentra bien posicionado para constituirse, nuevamente, en el eje dinámico de la recuperación, con China y Asia oriental desempeñando un papel protagónico. Las tendencias durante este proceso se orientarán al uso social racionalizado de las tecnologías electrónico-informáticas que impliquen el ahorro de costos en el corto y mediano plazos tanto para las empresas como para los gobiernos. México cuenta con un SE-I de mediano desarrollo, pero aún carece de capacidad dinamizadora e integradora del crecimiento de la economía interna; asimismo, inhibe el desarrollo de una infraestructura competitiva para la integración internacional y el desarrollo interno de procesos de conocimiento, por lo que su buen posicionamiento en la recuperación tenderá a actuar, paradójicamente, en contra de las reformas necesarias que permitan desplegar todas sus potencialidades de contribuir al desarrollo del país.

Palabras clave: sector electrónico-informático, crisis financiera y productiva global, México

* Investigador titular A de tiempo completo del IIEC-UNAM.

Correo Electrónico: serorgu@gmail.com

Agradezco el apoyo proporcionado por el PAPIT, proyecto IN306107-2 


\section{Abstract}

The effects of the global financial-production crisis on worldwide E-IS have been moderate: this sector is well positioned to reconstitute itself within the dynamic axis of recovery, with China and East Asia performing as rivals. The trends during this process will be oriented towards the socially rationalized use of electronics-informatics technologies that imply cost savings in the short and medium terms both for companies and governments. Mexico has a medium-developed E-IS, but still lacks the dynamic and integrated capacity of internal economic growth; at the same time, this inhibits the development of a competitive infrastructure for the international integration and internal development of knowledge processes, so that its good positioning in the recovery will tend to act, paradoxically, against the necessary reforms that will allow all of its potentialities to contribute towards the country's development.

Keywords: electronics-informatics sector (E-IS), global financial and production crisis, Mexico

\section{Résumé}

Les effets de la crise financière et productive globale sur le SE-I mondial ont été modérés: ce secteur se trouve en bonne position pour constituer, de nouveau, l'axe dynamique de la relance, avec la Chine et l'Asie orientale y jouant un rôle principal. Les tendances durant ce processus s'orienteront vers l'usage social rationnalisé des technologies électronicoinformatiques qui impliquent l'économie des coûts à court et moyen termes pour les entreprises comme pour les gouvernements. Le Mexique est doté d'un SE-I moyennement développé, mais il n'est pas encore capable de dynamiser et intégrer la croissance de l'économie interne; de telle sorte que se trouve inhibé le développement d'une infrastructure compétitive pour l'intégration internationale et le développement interne de processus de connaissance, ce pourquoi sa bonne position dans la relance tendra à agir, de manière paradoxale, à l'encontre des réformes nécessaires qui permettraient de déployer toutes les potentialités de contribuer au développement du pays.

Mots clés: secteur électronico-informatique, crise financière et productive globale, Mexique

\section{Resumo}

Os efeitos da crise financeiro-produtiva global sobre o SE-I mundial têm sido moderados: este setor acha-se bem posicionado para se constituir novamente, no eixo dinâmico da recuperação, com a China e a Ásia oriental desempenhando um papel protagônico. As tendências durante este processo orientar-se-ão ao uso social racionalizado das tecnologias electrônico-informáticas que impliquem a economia de custos no curto e médio prazos tanto para as empresas como para os governos. México conta com um SE-I de médio desenvolvimento, mas ainda carece de capacidade dinamizadora e integradora do crescimento da economia interna; além disso, inibe o desenvolvimento de uma infraestrutura competitiva para a integração internacional e o desenvolvimento interno de processos de conhecimento, motivo pelo qual o seu bom posicionamento na recuperação tenderá a atuar, paradoxalmente, contra as reformas necessárias que permitam desenvolver todas as suas potencialidades para contribuir para o desenvolvimento do país.

Palavras-chave: Setor Electrônico-Informático, crise financeira e produtiva global, México 


\section{Introducción}

n el marco de la crisis global actual, el estudio del sector electrónico-informáti-
co (SE-I) reviste especial importancia en cuanto éste sido el complejo industrial
y de servicios articulador y dinamizador del crecimiento y el comercio mundiales desde la década de 1990, razón por la cual se impone ahora la pregunta de en qué medida el SE-I contribuirá a la recuperación ${ }^{1}$.

En México, dar respuesta a este interrogante es prioritario: la industria electrónica ha pasado a constituir la principal actividad manufacturera exportadora; nuestro país se ubica como el undécimo exportador mundial y la industria de servicios de telecomunicaciones ha desplegado recientemente un intenso proceso de expansión internacional en América Latina.

Para estudiar esta problemática, la exposición se ha dividido en tres apartados: primero se ubica la crisis global actual en el marco de una nueva fase de desarrollo o capitalismo del conocimiento y se le caracteriza sucintamente, para después estudiar el SE-I en este marco y, finalmente, discutir la situación específica del SE-I en México y evaluar las posibilidades de que se convierta en un elemento dinámico de la recuperación.

\section{La crisis global en la perspectiva del desarrollo del capitalismo del conocimiento}

Nueva fase del desarrollo y capitalismo del conocimiento ${ }^{2}$

El capitalismo del conocimiento constituye una nueva fase de desarrollo, en la que el conocimiento se erige como la principal fuerza productiva del crecimiento económico, lo que a partir de la década de 1980 se traduce en un incremento notable del contenido en conocimiento de la producción social (Ordóñez, 2009)3.

1 En un documento reciente sobre las consecuencias de la crisis sobre el SE-I la International Telecommunication Union (ITU) afirma que éste enfrenta ingresos más volátiles después de a la crisis de 2001-2002, al depender por igual del gasto de los consumidores y las empresas. (En realidad, el sector ha enfrentado esta situación desde sus orígenes, por lo cual no cambia nada; por el contrario, ha articulado a actividades crecientes en su dinamismo. Véase Dabat y Ordóñez, 2009.)

2 Lo que enseguida se expone, constituye una síntesis de un desarrollo amplio y exhaustivo sobre el tema, llevado a cabo principalmente en Ordóñez, 2004 y 2009; Dabat y Ordóñez, 2009.

3 La aplicación de la ciencia y el conocimiento en la producción social no es novedosa en el capitalismo, al constituir uno de sus aspectos civilizadores, pero esta tendencia secular da un salto de calidad con la revolución tecnológica de la informática y las comunicaciones (Foray, 2000). 
Esta fase de desarrollo surge de una nueva articulación entre el sector científicoeducativo (SC-E) y el conjunto de la producción social, en la que el SC-E se convierte en una condición inmediata de la producción, por lo que la generación, circulación y acumulación del conocimiento tienden a incidir e involucrar a todos los ámbitos de la reproducción económica y social, lo que trasciende las instituciones científicoeducativas y las empresas e incluye nuevas instituciones económico-sociales de facto, formales e informales.

La nueva articulación entre el SC-E y la producción social es posible gracias a la revolución tecnológica de la informática y las telecomunicaciones, cuyo despliegue se traduce en una nueva base tecnológico-productiva que tiende a unirse con el toyotismo como nueva forma de dirección y organización de los procesos de trabajo, y que a diferencia del fordismo busca incorporar la calidad en los procesos productivos y en el producto social, para alcanzar así conocimiento, particularmente el conocimiento tácito de los operarios ${ }^{4}$.

Por consiguiente, el ciclo del conocimiento (producción, circulación y acumulación) que incluye al SC-E y la producción, circulación y el consumo sociales cuyo gran desafío histórico es la creación de nuevo valor a partir del conocimiento, pasará a formar una contratendencia a la caída tendencial de la tasa de ganancia (véanse Ordóñez, 2004 y 2009) 2.

En el ámbito macroeconómico, el despliegue de la revolución informática y de las comunicaciones trae consigo la integración de un nuevo complejo tecnológico-productivo, constituido por el conjunto de actividades industriales y de servicios articuladas por las tecnologías básicas del circuito integrado, el software y la digitalización, a ese complejo se le denomina sector electrónico-informático (SE-I), y su composición se presenta en el cuadro 1.

El SE-I se convierte en el nuevo núcleo articulador y dinamizador de la producción, el crecimiento y el comercio mundiales, en sustitución del complejo automotriz, metalmecánico petroquímico, propio de la fase de desarrollo fordista-keynesiana, lo que se traduce en un nuevo dinamismo económico o ciclo industrial, con fases

4 El toyotismo persigue objetivos contrarios al fordismo, puesto que se trata de producir pequeñas series de productos diferenciados y variados, incorporando las propuestas de mejora del proceso de trabajo y del producto por parte del operario (Coriat, 1991).

5 En el conjunto, la ley de la disminución tendencial de la tasa de ganancia sigue operando pero con una nueva contratendencia, que tendrá efectos directos sobre la división del trabajo entre las empresas en el contexto de las cadenas de valor. Para un estudio detallado, véan Ordóñez, 2004 y 2009. 
Cuadro 1.

Composición del sector electrónico-informático

\begin{tabular}{|c|c|c|c|}
\hline \multirow{2}{*}{ SUBSECTORES } & \multicolumn{3}{|c|}{ CÓDIGOS INTERNACIONALES } \\
\hline & CIIU & CUCI & NAICS \\
\hline COMPONENTES ELECTRÓNICOS BÁSICOS & $3671-9$ & 776 & \\
\hline Componentes activos (semiconductores) & 3674 & 776.3 y 776.4 & \\
\hline Componentes pasivos & $3675 / 9$ & & \\
\hline EQUIPO DE PROCESAMIENTO DE DATOS & 357 & 75 & 334 \\
\hline Computadoras & $3571 / 2,5$ y 7 & 752 & 3341 \\
\hline Sistema uniusuario a & 35715 & 752 & \\
\hline Sistema multiusuario $b$ & 35713 & 752 & \\
\hline Equipo periférico & 35771 & 752.5 & 3341 \\
\hline Equipo electrónico de oficina & $3578 / 9$ & 751 & \\
\hline Partes, piezas y acc. de computadoras y equipos & 35722 y 35772 & 759 & 33429 \\
\hline EQUIPO DE COMUNICACIONES & 48 & 764 & \\
\hline Telefonía & 481 y 3661 & 764.1 & 33421 \\
\hline Telefaxes & n.d & 764.13 & \\
\hline Equipo para redes & n.d & 884 & 3341 \\
\hline Equipo para radio y $T V$ & 3663 & 761 y 762 & 33422 \\
\hline EQUIPO INDUSTRIAL Y CIENTIFICO & & & \\
\hline Equipo electrónico de diseño y manufactura & & & 3332 \\
\hline Instrumentos de verificación, medida y análisis & 382 & 874 & 3345 \\
\hline Equipo médico & 384 & 774 & 3345 y 3391 \\
\hline EQUIPO ELECTRÓNICO DE CONSUMO & 36 & 76 & 334 \\
\hline Equipo de video & 365 & 761 & 3343 \\
\hline Equipo de audio & 365 & $762 / 63$ & 3343 \\
\hline Otros (juegos, instrumentos musicales, relojes) & 387 & 885 & 3346 \\
\hline EQUIPO MILITAR Y ESPACIAL & 376 & 792 & \\
\hline Equipo bélico & 376 & 891 & \\
\hline Equipo espacial & 376 & 792 & 3364 \\
\hline SOFTWARE Y SERVICIOS DE COMPUTACIÓN & $7371 / 9$ & $n . i$ & \\
\hline Servicios de programación & 7371 & n.i & $n . i$ \\
\hline Software empaquetado & 7372 & $n . i$ & n.i \\
\hline Servicios diversos a computación y computadora & 7379 & n.i & $n . i$ \\
\hline SERVICIOS DE COMUNICACIONES & 48 & n.i & 515 y 517 \\
\hline Telefonía por cable & $481 / 2$ y 9 & n.i & 5171 \\
\hline Telefonía inalámbrica & & n.i & 5172 \\
\hline Televisión & 4833 & $n . i$ & 5151 \\
\hline Satélites de comunicación & 484 & $n . i$ & 5174 \\
\hline
\end{tabular}

Fuentes: Bjorn Wellenius, "Electronics and the developing economies: introduction and overview" y 
expansivas más largas y de mayor crecimiento y fases recesivas más breves y menos profundas. El SE-I dinamiza la fase expansiva de los años noventa, determina la crisis mundial de 2001-2002 y encabeza la recuperación posterior ${ }^{6}$, a partir de un proceso de reestructuración tecnológico-productiva con consecuencias en su despliegue espacial mundial y su división internacional e interindustrial del trabajo (Dabat y Ordóñez, 2009).

Sin embargo, del capitalismo del conocimiento sólo se han desarrollado los aspectos tecnológico-productivos esenciales: todavía no ha surgido a escala mundial el "modelo de sociedad" o edificio social articulado que dé viabilidad histórica a la actual fase de desarrollo. Es decir, las transformaciones en curso en la economía aún no se han acompañado de cambios en la forma de organización y solución de conflictos entre las clases y los grupos sociales, ni en la ideología y la cultura -entendida como modo de vida-, que culminen en un nuevo tipo de Estado; estos últimos ámbitos del cambio tienen sus propios condicionantes y podrían no consumarse, abortando históricamente todo el proceso (Gramsci, 1932-1934, Cuaderno 1377 Ordóñez, 2004).

Caracterización de la crisis global actual en la perspectiva de la nueva fase de desarrollo

A continuación se ubica la crisis global en la perspectiva del desarrollo de la nueva fase, para lo cual se plantean los lineamientos generales de un marco de caracterización de la crisis financiera y productiva global, sin profundizar ampliamente en su estudio y sólo con un breve desarrollo explicativo, lo que tendrá el doble propósito

6 La anterior fase expansiva de la economía norteamericana tuvo una duración de nueve años (del segundo trimestre de 1991 al segundo trimestre de 2000), una tasa de crecimiento media de $4.1 \%$ de $1995-2000$ (contra $4.2 \%$ de $1959-1973$ ) y una tasa media de incremento de la productividad de $3.2 \%$ de $1995-2000$ (contra $2.9 \%$ de 1959-1973). El incremento acelerado de la productividad se tradujo en niveles más bajos de desempleo e inflación y en incrementos importantes del salario real (Baily, 2000; US-BEA). En cambio, en la contracción económica de 2001-2002 sólo hubo tres trimestres recesivos (2000-3, 2001-1 y 2001-3) y tuvo una duración de 10 trimestres (2000-3 a 2002-4) (US-BEA), aunque en ello incidió la situación de incertidumbre que se creó con posterioridad al 11 de septiembre de 2001, derivada de los atentados terroristas, la crisis de la aviación comercial, la guerra de Irak y el aumento en los precios del petróleo.

7 En términos de Gramsci, una nueva fase del capitalismo no puede constituirse sin la formación de un nuevo bloque histórico, es decir, sin la sustitución del grupo social hegemónico por aquel que dirige el cambio de una fase de desarrollo a otra (o de época histórica). La consideración de la relación dialéctica, y no determinista en un solo sentido, entre estructura y superestructura por Gramsci, lo hace romper con el determinismo económico de la Tercera Internacional, del mismo modo en que la articulación de la teoría shumpeteriana del ciclo industrial con la teoría gramsciana de las unidades orgánicas del capitalismo rompe con el determinismo tecnológico de la primera. 
de contribuir a contextualizar la crisis y servirá como base para la discusión de sus efectos sobre el SE-I, además de esbozar la posible función del sector en la recuperación en México.

En última instancia, la reciente crisis global es resultado del desarrollo de los elementos tecnológico-productivos fundamentales de una nueva fase antes de que hayan tenido lugar los cambios en la forma de organización y solución de los conflictos entre clases y grupos sociales (el ámbito de la política), en la ideología, la cultura y el conjunto de la trama institucional-social que culminarán en un nuevo tipo de Estado, Estos cambios tienen sus propios determinantes y deben posibilitar el pleno despliegue de las potencialidades contenidas en los nuevos fundamentos tecnológico-productivos.

Desde esta perspectiva, la crisis global actual parece determinar el agotamiento de una primera etapa del despliegue de la nueva fase de desarrollo, dominada por el capital financiero internacional, para dar paso, mediante la resolución de la crisis, a una segunda etapa, ahora dominada por el capital productivo. Esto implicará profundas reformas político-institucionales, que en el ámbito estrictamente económico estarán centradas en una redefinición del peso relativo del mercado, el Estado y las instituciones internacionales en el proceso de gobernancia económica nacional e internacional, así como en la emergencia de organizaciones de la sociedad civil que pugnarán por tener una nueva incidencia en ese proceso. Asímismo, se producirá un relativo debilitamiento de la hegemonía económico-política y militar de los Estados Unidos en favor de la multipolaridad, y aunque Asia se erigirá como la principal región emergente, otros países emergentes en el mundo también tendrán una posición relevante.

Los determinantes esenciales de la crisis son la autonomización y el crecimiento extremos del capital financiero frente al capital productivo, la informatización, automatización y el incremento inusitado de la velocidad de la circulación dineraria (Dabat, 2009), con la consecuente plétora de capital financiero global, provocada, en gran medida, por la ampliación de la esfera de valorización financiera resultado de la diversificación y el carácter más complejo de los nuevos instrumentos y agentes financieros. Todo ello implica una enorme difusión del riesgo financiero, sin que los agentes, particularmente los inversionistas individuales, cuenten con la información suficiente para hacerle frente (Kregel, 2008). En el fondo de todo se encuentra la "autorregulación privada" en la que se sustenta el neoliberalismo como modalidad de la globalización y del capitalismo del conocimiento, que hereda y racionaliza el conjunto de la trama institucional-social de la fase de desarrollo precedente, sin promover el surgimiento de una nueva. 
En ese marco, la crisis global actual se gesta como una crisis financiera en la que confluyen tanto fenómenos nuevos como las ya señaladas informatización automatización e incremento de la circulación dineraria, el nuevo capital financiero y su gestión del mercado secundario de las hipotecas, con fenómenos tradicionales y de largo plazo como la disminución generalizada de las tasas de interés, como medida de política monetaria de estímulo de la producción y el consumo en situación recesiva, y la existencia de plétoras de capital financiero en las etapas iniciales de conformación de una nueva fase de desarrollo (Kregel, 2008; Pérez, 2009; Dabat, 2009; Muci Facchin, 2008). Por su amplitud y profundidad, la actual crisis financiera es un suceso inédito, aun cuando por sus efectos sobre la producción sus implicaciones parezcan relativamente limitadas, comparadas con las de la Gran Depresión de la década de 1930 (Shirai, 2009; Reinhart y Kenneth, 2008).

La crisis financiera se originó en el sector inmobiliario de los EEUU. Ante la disminución generalizada de las tasas de interés promovida por los bancos centrales de los principales países desarrollados que siguió a la crisis de 2001-2002 y, particularmente, a los atentados de septiembre de 2001, una plétora de nuevo capital financiero incursionó en el sector inmobiliario de los Estados Unidos y otros países, como Reino Unido, Canadá, Australia (ADB Economics, 2008) y España. Tuvo lugar entonces un auge desmedido de la industria de la construcción, que arrastró a un conjunto de industrias directamente encadenadas (insumos materiales y de conocimiento) y contribuyó en alguna medida al alza en los precios internacionales de algunos commodities metálicos y materiales de construcción. ${ }^{8}$ Asimismo se produjo un incremento y luego la sobrevaluación de los precios de las acciones de las grandes empresas constructoras —evidente en los máximos alcanzados por el Índice de Construcción de Vivienda del Dow Jones ${ }^{9}$ en julio de 2005 en los 1100 puntos, en relación con su nivel de 297 en marzo de $2003^{10}$ - Sobre esta base se gesta y despliega un complejo y enorme circuito financiero global que es responsable del exacerbado aumento de la burbuja inmobiliaria y en cuyos extremos se encuentran, por una parte, los compradores de bienes raíces financiados con préstamos hipotecarios, y, por la otra, los inversionistas privados (fon-

$8 \quad$ El índice de precios de las commodities metálicas alcanza su máximo entre mayo de 2007 y marzo de 2008, oscilando entre 205 y $201(2005=100)$, y se ubica en su nivel actual (junio 2009) en 126, e incluye al cobre, aluminio, acero, estaño, níquel, zinc, plomo y uranio, (FMI: http://www.indexmundi.com/commodities).

9 Se trata de un índice de inversiones en empresas de la construcción en los EEUU, calculado a partir del precio de las acciones y su rendimiento.

10 O su nivel actual de 261 a finales de julio de 2009. 
dos mutuales, de retiro, de inversión, hedge funds, etc. o inversionistas individuales), que invierten en complejos instrumentos financieros derivados de las hipotecas.

En el núcleo del circuito financiero se encuentra la operación de dos instrumentos financieros surgidos a inicios de la década de 1990, ambos componentes funcionales básicos de la operación del nuevo capital financiero: la titularización o securitización del crédito, y los derivados. La titularización del crédito o securities implica la posibilidad de convertir un activo financiero asociado a un flujo recurrente de efectivo (como el caso de las hipotecas u otros tipos de créditos) en papel comercial, lo que supone la metamorfosis de los activos no líquidos en líquidos o dinero bancario, bajo la lógica subyacente de antevalidar a activos presentes flujos de efectivo futuros (Muci Facchín, 2008). Implica, por tanto, una acción de intermediación del capital financiero y la consecuente autonomización en un grado superior del capital financiero respecto del capital productivo, al propiciar el desdoblamiento y la ramificación múltiple del circuito de crédito, puesto que disocia el vínculo directo entre acreedor originario y deudor, con lo que el pago sobre el activo ya no depende de la situación financiera del emisor, sino de la propia "calidad" del activo (Muci Facchín, 2008) ${ }^{11}$.

Específicamente, la titularización del crédito hipotecario implica el desarrollo del mercado secundario de hipotecas con la incursión de nuevos agentes financieros, como los bancos de inversión, las entidades hipotecarias, las calificadoras crediticias, los inversionistas privados, etc., que reducen la participación en el mercado de las empresas respaldadas por el gobierno (Ginnie Mae, Fannie Mae y Freddie Mac) -de casi 80\% en 2003 a alrededor de $45 \%$ en 2005 (Kregel, 2008) ${ }^{12}$. El último paso en este proceso consiste en el crecimiento de los préstamos subprime (préstamos de baja calificación crediticia) a medida que los precios de las viviendas continúan en aumento, y se convierten en el segmento de más rápido crecimiento al pasar de $2.4 \%$ del total de préstamos hipotecarios en 2000 a $13.4 \%$ en vísperas del estallido de la burbuja (junio de 2006) ${ }^{13}$.

11 Las securities permiten a los bancos sacar los riesgos de sus hojas de balance, por medio de la formación de "paquetes" de préstamos y su recomercialización a diversos inversionistas [Engdhal, www.global research.ca.].

12 Proceso que cambia su lógica de operación del mercado de "comprar y mantener" (ingreso generado por la diferencia entre el interés de los depósitos y de los préstamos) a otra de "intercambio", a partir del ingreso generado entre el precio de compra y de venta del instrumento; el ingreso de la institución depende, por tanto, de la velocidad y el volumen de los instrumentos intercambiados y no de la solvencia del deudor (Kregel, 2008).

13 Los préstamos subprime no fueron más que la punta del iceberg y el punto más débil del circuito financiero, fenómeno que se agravó en el periodo anterior al estallido de la burbuja inmobiliaria y se produjo sobre la base del incremento continuo del precio de los bienes raíces y la abundancia de capital financiero en el sector. 
Por su parte, los instrumentos derivados son aquellos cuyo precio depende del precio de un activo real o ficticio subyacente, por lo que constituyen una forma muy desarrollada de capital ficticio ${ }^{14}$, como representación de casi cualquier tipo de capital real o mercancía en el presente o en el futuro, o, incluso, de diversas formas de capital ficticio (representación de representación de valor de capital), lo que eleva el monto del valor representado por los instrumentos derivados a escala mundial a US\$ 596000 billones o 908\% del PIB mundial en 2007 (FMI-Global Financial Stability Report, 2007).

La combinación de ambos instrumentos resulta en las obligaciones sobre hipotecas colateralizadas (collaterized mortgage obligations, CMO), que es un derivado de la posible protección o exposición del inversionista a diversos riesgos (como el pago anticipado de la hipoteca), lo que permite la multiplicación de la representación de capital y, por consiguiente, la reproducción extrema del capital ficticio respaldado en hipotecas a medida que los "vehículos de inversión" (special investment vehicles, SIV, o special purpose vehicle, SPV), en los que hipotecas de los más diversos orígenes, tipos y calidad crediticia eran reunidas y "empaquetadas", cambiaban de manos entre múltiples agentes como medio de pago, multiplicando con ello el valor capital representado y difundiendo simultáneamente el riesgo entre estos agentes a lo largo de un circuito financiero desdoblado y con ramificaciones múltiples, lo que desde la perspectiva del emisor originario, por el contrario, daba la impresión de aminorar el riesgo implícito ${ }^{15}$.

Estos instrumentos combinados dan lugar a la constitución de un enorme y complejo circuito financiero; su despliegue y desarticulación posterior se describirán brevemente, con especial énfasis en la función y ubicación de los principales agentes involucrados:

a) Los compradores de bienes raíces mediante hipotecas, entre los que se incluye a los compradores especulativos. Como ya se mencionó, los prestamistas subprime fue-

14 El capital ficticio es capital creado por la simple fabricación de medios de circulación y consiste en letras de cambio o promesas de pago que circulan como dinero comercial hasta su vencimiento. Se extiende mediante el relevo de otras antes del vencimiento de las primeras letras de cambio, y no son más que réplicas de papel de capital que muchas veces ya existe, pero que para sus poseedores actúa como capital, dado que constituye mercancías vendibles y, por tanto, reconvertibles en capital (Marx, 1894).

15 De lo que se desprende la extrema dificultad para calificar la calidad crediticia y el riesgo implícito en cada SIV o SPV. Los derivados respaldados en securities hipotecarias residenciales (residential mortgage-backed securities) quitaban el riesgo del balance de los bancos y permitían ocultar pérdidas, con lo que podían seguir expandiendo el crédito en busca de comisiones y gastos que inflaban las ganancias (ABD Economics, 2008). 
ron los de más rápido crecimiento a medida que los precios de las viviendas continuaban aumentando. Sus préstamos eran a tasas ajustables en más del 50\%, a diferencia del $18 \%$ de los préstamos prime, frecuentemente a tres o más puntos porcentuales por arriba de éstos; por ello se convirtieron en los préstamos más redituables y, en consecuencia, fueron los más buscados por los bancos (New York Times, 06/12/2006) ${ }^{16}$.

b) Los bancos y entidades hipotecarias que emiten deuda hipotecaria, entre los que se encontraban las entidades comerciales más importantes de los EEUU, como Citigroup, JP Morgan Chase, Bank of America, Wells Fargo y Washington Mutual Bank. No obstante haber perdido participación en el mercado de hipotecas -de alrededor del $50 \%$ a inicios de los noventa a 30\% en el tercer semestre de 2008- en beneficio de los bancos de inversión (véase infra), han recibido inyecciones de capital por parte del gobierno o se han absorbido recíprocamente entre ellos ${ }^{17}$, ante las grandes pérdidas provocadas por la fuerte exposición a la deuda hipotecaria, la paralización del crédito y la caída en picada de su precio accionario, proceso que ha favorecido principalmente a JP Morgan Chase.

c) Los intermediarios hipotecarios como Fannie Mae y Freddy Mac, que contribuyeron a hacer disponible el crédito hipotecario para individuos y hogares que de otro modo no habrían calificado (con lo cual ampliaron la demanda de hipotecas), y compraban créditos hipotecarios a los bancos comerciales para revenderlos a los bancos de inversión. Estos intermediarios aumentaron su participación en la deuda hipotecaria de $25 \%$ en 1990 a 41.4\% en 2007 (aunque, como ya se mencionó, esta participación disminuyó relativamente a partir de 2003), además de su exposición a las securities apoyadas en hipotecas, al pasar de respaldar de 33\% a $88 \%$ del total de 2006-2 a 2008-1 (ADB Economics, 2008) ${ }^{18}$.

16 El vertiginoso incremento de los préstamos subprime hasta convertirse en los de más rápido crecimiento fue facilitado por la invención de un software propietario que facilitaba la localización de reportes crediticios en línea en tiempo real y calculaba los riesgos de incumplimiento, eliminando un proceso de contratación de préstamos que tardaba varias semanas e involucraba a un corredor que reunía historias crediticias y comprobantes de ingresos. El software fue vendido a corredores de préstamos subprime como First Franklin, lo que le permitió aumentar las solicitudes de préstamos siete veces en 2005 y generar US $\$ 450$ mmd en préstamos subprime desde 1999 (The New York Times, 23/05/2007).

17 El exponente más conocido ahora es el Washington Mutual Bank, la mayor quiebra bancaria en los EEUU, al constituir el mayor banco (el sexto más grande) con una gran exposición a la deuda hipotecaria subprime o de baja calificación crediticia. El banco fue intervenido por el gobierno y vendido a JP Morgan Chase por US\$ $1.9 \mathrm{mmd}$ el 24 de septiembre (The New York Times, 25/09/2008). Por otra parte, Wells Fargo adquirió el Wachovia Bank en octubre por US\$ $15.1 \mathrm{mmd}$, desplazando de la puja a Citigroup.

18 Se trata de intermediarios respaldados por el gobierno. En agosto de 2008, los precios de sus acciones sufrieron una vertigionosa caída a causa del deterioro del mercado de bienes raíces. 
d) Los bancos de inversión Merrill Lynch, Goldman Sachs, Morgan Stanley, Bear Sterns y Lehman Brothers, que adquirían las hipotecas de los bancos comerciales y las titularizaban, convirtiéndolas en vehículos de inversión con crecientes radios de apalancamiento que llegaron a oscilar en torno de 30\% en 2007 (salvo Goldman Sachs, con 25\%) (www.wikipedia.org). Estas acciones determinaron su papel central en el circuito financiero y, con la precipitación de la crisis, su desaparición como agentes financieros separados de los bancos comerciales, al capitalizar $68 \%$ de la deuda hipotecaria en el tercer trimestre de 2008 (The New York Times, 20/02/2009) ${ }^{19}$.

e) Las agencias calificadoras de créditos, Moody's, Standard and Poors y Fitch, y las aseguradoras especializadas (monoline insurers), como American International Group Inc. (AIG), encargadas, respectivamente, de calificar la calidad y el riesgo crediticio de las securities y, en caso de no alcanzar la calificación AAA, de asegurarlas. El mercado de las coberturas de riesgo de las securities protegidas por hipotecas (credit default swaps, CDS) se multiplicó, pero las garantías ofrecidas por estas grandes aseguradoras resultaron insostenibles cuando los precios de las viviendas comenzaron a disminuir en 2007 (véase gráfica 1$)^{20}$.

f) Los inversionistas privados o institucionales (fondos mutuales, de retiro, de inversión, hedge funds, private equity funds, etc.), que invirtieron en SIV o SPV y los intercambiaron. Sin embargo, la demanda de estos instrumentos disminuyó cuando la FED incrementó las tasas de interés para contrarrestar la inflación (hasta un máximo

Para septiembre, sus acciones fueron retiradas del mercado y el gobierno tomó el control de ambas entidades.

19 El primer acontecimiento palpable de la crisis fue la quiebra de dos hedge funds de Bear Stearns en junio de 2007; en marzo del año siguiente, la FED asumió US\$ 30 mmd de deuda de esta entidad y el diseño de una arquitectura de venta a JP Morgan Chase. En septiembre se precipitaron los acontecimientos: Lehman Brothers quebró; mientras que Morgan Stanley decidió vender 20\% de su capital al Mitsubishi Bank y Goldman Sachs aceptó una inyección de capital por parte del inversionista privado Warren Buffet, a cambio de una participación en su capital. Tanto Morgan Stanley como Goldman Sachs evitaron la quiebra gracias a que abandonaron su estatus de bancos de inversión para convertirse en bancos comerciales. Por su parte, Merrill Lynch resolvió venderse al Bank of America para evitar el escrutinio gubernamental impuesto a Lehman y Bear, lo que en su conjunto cierra la etapa de separación entre los bancos de inversión y los comerciales en el sistema financiero norteamericano, abierta con la regulación de 1930 (www.nytimes.com).

20 El gobierno ha tomado el control de $80 \%$ del capital de AIG, resultado del rescate de la compañía con un costo total de US $\$ 150 \mathrm{mmd}$, ante la caída libre del precio de sus acciones desde septiembre de 2008 (precedida por una tendencia a la baja desde octubre de 2007), debido a su alta exposición en seguros sobre hipotecas. En marzo de 2009, la aseguradora vuelve a aparecer en primera plana cuando se revela que del dinero de los contribuyentes US \$160 millones fueron destinados al pago de bonos a los ejecutivos, desatando el furor del público y de los legisladores estadounidenses. 
de $5.25 \%$ en 2006), y porque pudieron percibir el alza de la burbuja inmobiliaria y su inevitable estallido. Todo ello fue el inicio de su salida masiva del mercado, que en un primer momento provocó la desaceleración del incremento de los precios de vivienda y luego el estallido de la burbuja inmobiliaria, con la consiguiente caída del precio de los instrumentos financieros y el aumento de las tasas de interés de las hipotecas. Simultáneamente, un descenso en picada de los precios de los bienes raíces ocasionó el incremento de las suspensiones de pago de las hipotecas y la paralización del enorme circuito financiero de las securities respaldadas en hipotecas ${ }^{21}$ (gráfica 1). Estas circunstancias precipitaron la crisis en septiembre de 2008 y una estampida de los mercados dinerarios, que los arrojaría a la búsqueda de inversiones seguras en bonos del tesoro, metales preciosos, etcétera.

Gráfica 1.

EEUU: aumento de precios de vivienda y tasa de incumplimiento en pago de crédit os (1998-2008)

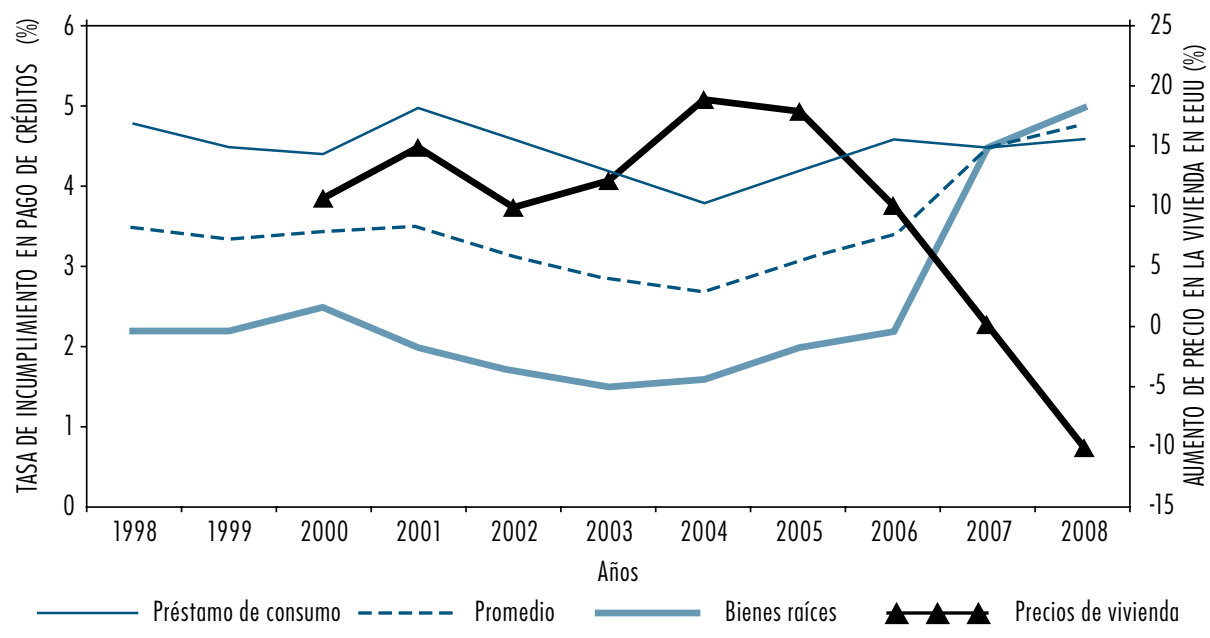

Fuente: Board of Governors of the Federal Reserve System, 2008,

"Statistics: relases and historical data: www.federal reserve.gov/releases/, y standard \& poors, 2008,

"case/shiller home prices indices": www2.standardandpoors.com/portal/site/sp/en/us/page.topic/indices.

21 En 1994, Greenspan advertía que los derivados podrían amplificar las crisis, debido a que reúnen las fortunas de muchas instituciones independientes: "La notable eficiencia involucrada en esto significa que si una crisis tuviera lugar, esa crisis se transmitiría a un paso mucho mayor y con acrecentada virulencia". [Citado por The New York Times, 9/10/2008.]. 
De lo anterior se identifican las siguientes etapas de gestación y despliegue de la crisis:

1. El sector inmobiliario en los EEUU se desacelera a finales de 2005 y la burbuja inmobiliaria estalla hacia mediados de 2006 (véase gráfica 1). Múltiples y complejos mecanismos de transmisión dan lugar rápidamente a una crisis financiera global, caracterizada por el congelamiento generalizado del crédito desde mediados de 2007 , proceso que se refuerza por la existencia de algunos focos (activos) periféricos en países como Reino Unido, Canadá, Australia (ADB Economics, 2008) y España, que sufren el estallido de sus propias burbujas inmobiliarias en 2007. Además, un alto nivel de endeudamiento bancario y la exposición a activos tóxicos contribuyen a la difundir y profundizar del carácter global de la crisis.

2. Las sucesivas quiebras, adquisiciones e intervenciones gubernamentales producidas en el circuito de crédito desde septiembre de 2008 provocan un pánico generalizado que transforma la paralización del circuito financiero de las securities hipotecarias en una virtual paralización del conjunto de los circuitos financieros globales, lo que convierte a la crisis financiera también en una crisis productiva.

3. La crisis financiero-productiva adquiere una dimensión enteramente global al extenderse a los países en desarrollo; pese a la poca exposición de sus sistemas financieros y sus empresas a los activos tóxicos, son víctimas de la paralización generalizada del crédito, la contracción de la demanda y del pánico de los inversionistas en los mercados cambiarios, lo que trae consigo la devaluación generalizada de sus monedas, proceso acentuado en países con un alto nivel de endeudamiento bancario y grandes déficit comerciales y fiscales, como Islandia, Pakistán, Hungría, República Checa, Ucrania, Belarús, Letonia, Serbia, Rumania, etcétera ${ }^{22}$.

Los primeros intentos de corrección de la crisis se han orientado a fortalecer la capacidad de regulación del Estado frente al mercado, no sólo en la esfera financiera sino en diversos ámbitos. Primero, la regulación del sistema financiero global y la reforma de instituciones internacionales como el Banco Mundial, el FMI y el

22 Pakistán, Islandia, Hungría y Ucrania recibieron paquetes de rescate del FMI en 2008, y el resto de los países enunciados en 2009; México se ha declarado "dispuesto" a recibir US\$ 47 mmd. La crisis ha revivido al FMI (que hasta inicios de abril de 2009 ha proporcionado recursos a 13 países afectados), cuyo papel parecía irrelevante tan sólo hace unos meses, con la inyección de fondos por parte de países emergentes como China, Rusia y la India, que acumularon una gran cantidad de reservas durante el periodo previo a la crisis y están interesados en aprovechar la coyuntura abierta por ésta para incrementar su peso político internacional. 
$\mathrm{G}^{23}$. Segundo, al capitalizar a las instituciones financieras afectadas por la crisis, los gobiernos se han convertido en propietarios de su capital social, en muchos casos mayoritariamente; además, en muchos países el respaldo gubernamental de los depósitos bancarios otorga al gobierno el derecho de intervenir gerencialmente las instituciones en riesgo, lo que en los EEUU derivó en su momento en la posibilidad de una nacionalización bancaria. Tercero, en los EEUU el rescate gubernamental de la industria automotriz (General Motors y Chrysler) ha convertido al gobierno en una especie de supervisor de la industria, que le está imponiendo drásticas directrices para su desarrollo futuro, como dar prioridad a la fabricación de automóviles con nueva tecnología híbrida o eléctrica. Cuarto, el plan de estímulos fiscales en los EEUU incluye incentivos para la creación de una nueva infraestructura basada en diversas fuentes de energía renovable, así como la promoción del desarrollo de la infraestructura electrónico-informática y, particularmente, de telecomunicaciones, además del desarrollo de la infraestructura tradicional ${ }^{24}$.

\section{El sector electrónico-informático mundial ante la crisis}

Al constituir una crisis financiera global centrada en el sector inmobiliario y las SIV y SPV respaldados en hipotecas, sus repercusiones previsibles directas sobre el SE-I mundial derivan de dos procesos íntimamente relacionados: 1) los efectos recesivos sobre el conjunto de la actividad económica, a la cual el sector provee de insumos productivos en una relación de articulación "hacia delante", además de la reducción de la demanda sobre los productos finales del propio sector, resultado de una disminución de la demanda mundial; y 2) la escasez y posteriormente el virtual congelamiento del crédito mundial, con repercusiones adicionales sobre una contracción generalizada en la inversión en el sector y en el equipo electrónico-informático en el conjunto de la economía.

23 Esta iniciativa suscitó posiciones divergentes: para salir de la recesión, los Estados Unidos y la Gran Bretaña enfatizan en la necesidad de paquetes de estímulos gubernamentales coordinados; por el contrario, Francia y Alemania consideran prioritaria la regulación del capital financiero, mientras que los países emergentes como China, Rusia, la India y Brasil defienden la reforma de las instituciones internacionales, para que se les reconozca un nuevo peso político internacional de acuerdo con su potencia económica

24 El plan prevé el desembolso de US $\$ 16.8 \mathrm{mmd}$ para la promoción del desarrollo de fuentes renovables de energía; US \$20 mmd para la digitalización de los historiales médicos de los pacientes y su puesta y acceso en línea; US $\$ 11 \mathrm{mmd}$ para el desarrollo de una red nacional inteligente de monitoreo y control del consumo eléctrico; y US \$6 mmd para el despliegue de nuevas redes y el acceso universal de banda ancha. Se prevé que el gasto en infraestructura electrónico-informática creará alrededor de 940000 empleos. 
Lo anterior tendrá efectos sobre las tendencias de desarrollo del SE-I posteriores a la actual crisis, cuyo análisis y valoración requiere partir de las tendencias recientes de desarrollo del sector, derivadas de su reestructuración tecnológico-productiva y su redespliegue espacial posterior a la crisis mundial de 2001-2002, la cual tuvo su epicentro en el SE-I mundial, pero particularmente en el de los EEUU (Dabat y Ordóñez, 2009). La reestructuración tecnológico-productiva ha consistido en una mayor integración de los principales fundamentos tecnológicos del sector, que se traduce en la expansión de los radios de acción del microprocesador y la digitalización, una nueva interacción entre dispositivos y el desarrollo intenso de las redes de interconexión y de internet $-\mathrm{y}$, por ende, del software-, reforzados por la emergencia y confluencia de nuevas tecnologías con la electrónica, como la nanotecnología o la bioelectrónica. Lo anterior ha implicado que los productos y subsectores productivos "tradicionales" en el periodo precedente a la década de 1990 se vean sacudidos por el rápido ascenso de una nueva generación de instrumentos industriales, científicos, profesionales y militares de precisión, dispositivos electrónicos de consumo de nuevo tipo, la difusión masiva del microcontrolador a un conjunto amplísimo de dispositivos eléctricos, mecánicos, de detección y control, una nueva dimensión de internet y las redes en la integración de la interacción y operación de dispositivos electrónicos de muy diversa índole, así como la tendencia a sustituir el software propietario por el software libre o de fuente abierta, particularmente en el ámbito del software empresarial y los servidores.

En su dimensión espacial, la reestructuración se ha fundamentado en la ampliación -incluso mayor que en el periodo precedente- de la importancia de las fases de concepción y diseño de los productos y procesos, en relación con las manufactureras propiamente dichas, lo que se traduce en un incremento de los tiempos y gastos en investigación y desarrollo dentro del ciclo de producción y, por tanto, en un aumento sustancial de los requerimientos de trabajo intelectual. Por consiguiente, ha cobrado nueva importancia económica el abaratamiento de los costes de este tipo de trabajo, lo cual conlleva a una nueva tendencia a la relocalización subcontratación internacionales de actividades de investigación y desarrollo, concepción y diseño no esenciales dentro del ciclo de producción, o manufactureras y servicios de mayor valor agregado, en países de desarrollo intermedio que cuentan con sectores científico-educativos con cierto desarrollo, fuerza de trabajo calificada, infraestructura informática y de telecomunicaciones relativamente avanzada y ventajas competitivas de tipo cultural o lingüístico (Dabat y Ordóñez, 2009) ${ }^{25}$.

25 Por tanto, la intensificación generalizada de los procesos de relocalización-subcontratación 
En general, todas estas tendencias continuarán avanzando, aunque destacarán aquellas que impliquen un uso más racional desde el punto de vista social de la base tecnológica y que conlleven un ahorro en los gastos operativos de las empresas individuales y los gobiernos en el corto y mediano plazos, abriéndose, adicionalmente, la posibilidad de la irrupción de nuevas tecnologías que actúen en ese sentido. Las tendencias que previsiblemente se acentuarán son:

a) La cooperación entre computadoras y el desarrollo de las redes de interconexión y de internet en su dimensión integradora de la interacción y operación de dispositivos, así como soporte de nuevos servicios que adquieren una base tecnológica digital y que están basados en el desarrollo de Internet-2, como la telemedicina, bibliotecas digitales, laboratorios virtuales, manipulación a distancia, etc., tendencias en las que destacan desarrollos recientes como el cloud computing, la virtualización de servidores, la computación social ${ }^{26}$, el monitoreo y control de procesos a distancia en tiempo real y, adicionalmente, la convergencia de servicios empresariales con base en redes de internet (videoconferencia, audioconferencia, espacios públicos de video y audio conferencia, etcéctera $)^{27}$.

internacionales incluye tanto actividades intensivas en conocimiento y de alto valor agregado como actividades tradicionales, con menor nivel de calificación, protagonizada por países pioneros en el desarrollo de ese tipo de estrategias empresariales como los EEUU, así como por países más rezagados en su aplicación como los europeos y, particularmente, Japón.

26 Cloud computing se refiere a la computación basada en el desarrollo y el uso de internet, en que las aplicaciones informáticas y de telecomunicaciones son proporcionadas como servicios. La computación social consiste en sistemas que soportan la reunión, representación, procesamiento, uso y diseminación de la información que es distribuida a través de colectividades sociales, como equipos, comunidades, organizaciones y mercados. Sobre todo, la información no es "anónima" sino significativa, precisamente porque está ligada a gente que a su vez está vinculada a otra gente [Wikipedia, 13/10/2008]. La virtualización de servidores consiste en la capacidad de dividir simultáneamente la funcionalidad de un servidor, con lo que se obtienen aplicaciones correspondientes a múltiples servidores u otros dispositivos que coordinan la funcionalidad de diversas computadoras, como es el caso de un sistema de interconexión de voz y datos basados en protocolo de internet.

27 Se prevé que los gobiernos se constituirán en agentes activos en el financiamiento y despliegue de la inversión en nuevas redes de telecomunicaciones (ITU, 2009), del mismo modo en que los operadores de telecomunicaciones están compartiendo redes (como Vodafone y Telefónica en Europa) para abatir los costos de operación y mantenimiento. Asimismo, los principales operadores de telecomunicaciones en los EEUU, Europa, Australia y China planean proporcionar un nuevo servicio a las empresas: la subcontratación de sus redes computacionales, que podría representarles grandes ahorros en costos fijos (CNET, 03/04/2009). Ello se relaciona con la tendencia de los operadores a subcontratar la operación y el mantenimiento de sus redes a los productores de equipo como Eriksson y Nokia-Siemens (The New York Times, 13/04/2009). 
b) La tendencia a la sustitución de software propietario por software libre y software de fuente abierta y la distribución de software como servicio, procesos que se complementan con el desarrollo de la cooperación entre computadoras y el de las redes de interconexión ${ }^{28}$.

c) La relocalización-subcontratación de actividades de investigación y desarrollo, concepción y diseño o manufactureras y servicios de mayor valor agregado (a China y Asia oriental, y también a países de Europa central, los bálticos, la Comunidad de Estados Independientes, la India y el Medio Oriente, etc), así como de las actividades tradicionales, de bajo contenido en conocimiento y valor agregado (a países como Vietnam, de Medio Oriente y de África), ya que de esa manera es posible reducir $\operatorname{costos}^{29}$. En este proceso, México podría desempeñar un papel importante en la relocalizaciónsubcontratación de procesos intensivos en conocimiento desde los Estados Unidos.

En términos generales, el SE-I no ha resultado tan afectado por la crisis como las industrias del antiguo complejo industrial articulador y dinamizador del crecimiento, particularmente las industrias automotriz y química. Enseguida, se esbozan las repercusiones en la dinámica interna del sector: 1) los ingresos de las principales empresas de actividades industriales han sufrido más daño que los de las empresas de las actividades de servicios (véase cuadro 1); 2) la región asiática, la más importante región emergente del periodo posterior a la crisis de 2001-2002, ha resultado particularmente perjudicada: la contracción de la demanda mundial de los productos electrónicos exportados por China redujo las importaciones chinas de partes y componentes, actividad que se había convertido en uno de los principales ejes dinámicos de la articulación de las cadenas de valor en la región, y que afectó particularmente a Japón por la revaluación del yen, pero también a países como Taiwán, Hong Kong, Corea y Singapur ${ }^{30}$; 3) la inversión en I\&D se ha visto menos perjudicada que la

28 El desplazamiento de la capacidad de procesamiento de información de la PC o de los centros de cómputo de las empresas hacia internet que supone el cloud computing, implica la instalación de grandes centros de datos por parte de las empresas que proporcionan este servicio (empresas como Google o IBM). estos centros de datos tienden a operar con software libre o de fuente abierta, ya que les permite economizar costos. Y eso conlleva a proporcionar las nuevas funcionalidades de software como un servicio.

29 Un reporte reciente citado por ITU (2009) revela que cerca de la mitad de las empresas han recortado su presupuesto para 2008 en tecnologías electrónico-informáticas, mientras que sólo una quinta parte lo ha hecho para la subcontratación de servicios basados en las mismas tecnologías.

30 Las relativamente altas tasas de interés en Japón hacen del yen una moneda de refugio en tiempos de crisis, lo cual ha tendido a aumentar su cotización respecto de otras monedas "duras". La producción en Japón y Taiwán se contrajo en $40 \%$ a inicios del año y el comercio interasiático del SE-I se contrajo de $25 \%$ al $40 \%$ entre 2008 y lo que va de 2009 (OCDE, 2009). 
producción o el empleo, debido a una buena situación financiera de las empresas en términos generales y a la importancia fundamental de los procesos de innovación en la competencia interna, y 4) la contracción de las actividades industriales es menor que durante la crisis de 2001-2002, aun cuando la de las actividades de servicios es mayor, no obstante, el coeficiente de efectivo a deuda del conjunto de las empresas en general es más favorable que en la crisis precedente (OCDE, 2009).

Para estudiar con detalle los efectos de la crisis sobre el sector, el análisis se centrará fundamentalmente en la industria electrónica (IE) y en la industria de servicios de telecomunicaciones (ISTC), no sólo porque son las actividades sobre las que hay más información disponible sino porque son las principales actividades por las que México se integra en la división internacional del trabajo en torno al SE-I (Ordóñez, 2009; y Dabat y Ordóñez, 2009).

\section{La industria electrónica}

En sus inicios, la crisis provocó una disminución del comercio mundial de la IE de alrededor de -3.5\% en 2007 (WITS, 2008) y una contracción de los ingresos trimestrales de las 10 principales empresas de cada una de las ramas que conforman la industria de $-3.2 \%$ durante 2008 y el primer trimestre de 2009 (datos trimestrales en relación con el mismo trimestre del año precedente) (OCDE, 2009).

La gráfica 2 muestra que los ingresos han sufrido una caída más fuerte en la industria de semiconductores, seguida del equipo de cómputo y oficina y la electrónica de consumo, mientras que el equipo de telecomunicaciones sólo experimentó una fuerte contracción en el primer trimestre de 2009; en todos los grupos, las caídas más fuertes se produjeron en el cuarto trimestre de 2008 y el primero de 2009.

\section{Gráfica 2.}

Crecimiento trimestral del ingreso de las 10 principales empresas en ramas de la electrónica

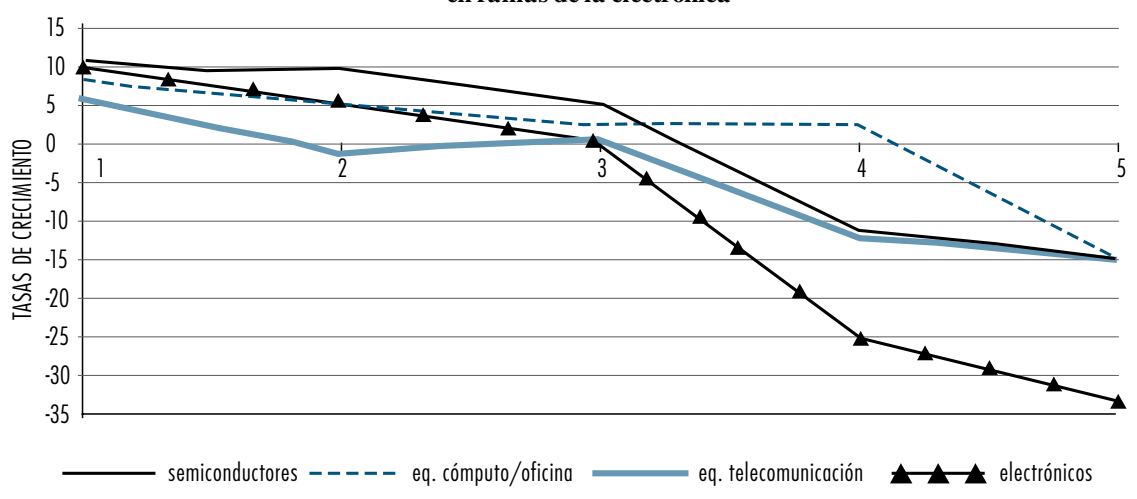

Fuente: elaboración propia a partir de los datos que presenta la OCDE en el documento: "The impact of the crisis on ICTS and their role in the recovery", 28 de julio de 2009, dsti/iccp/ie(2009)1/final. 
En lo que respecta a la demanda, en 2008 continuó creciendo el gasto global en equipo electrónico-informático a un ritmo de $6.1 \%$, y la demanda global de productos electrónicos se elevó 4\% (US\$ 1246 trillones), aun cuando la demanda de semiconductores se contrajo en -3\% ${ }^{31}$. Para 2009 se prevé que se verifique una fuerte contracción de $-6 \%$ en la demanda global y de $-3.8 \%$ en el gasto global en equipo (mayor que la de 2001 de $-2.1 \%)^{32}$.

Por su parte, la inversión en I\&D se ha visto menos afectada y se observa un patrón de comportamiento comparativo entre las ramas similar a los ingresos, pero con un importante crecimiento de la inversión, aun en el tercer trimestre de 2008, en la electrónica de consumo y el equipo de telecomunicaciones de alrededor de 5\% (gráfica 3).

Gráfica 3.

Crecimiento trimestral de la inversión de la 10 principales empresas en ramas de la electrónica

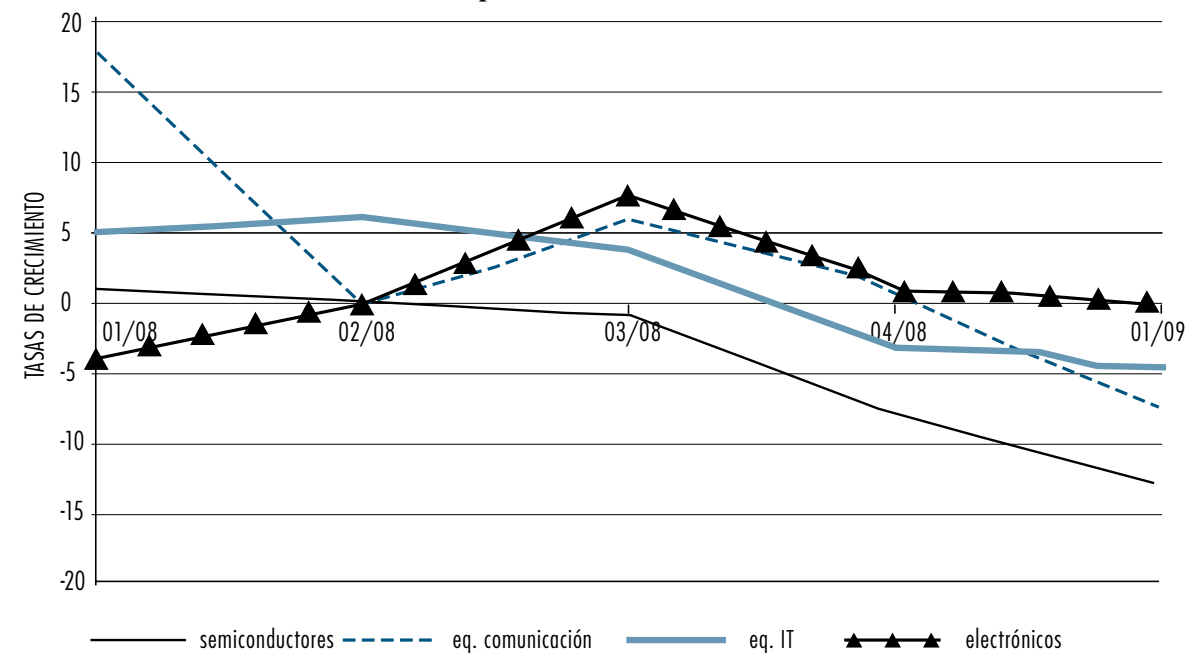

Fuente: elaboración propia a partir de los datos que presenta la OCDE en el documento: The im pact of the crisis on ICTS and their role in the recovery, 28 de julio de 2009. DSTI/ICCP/IE(2009) Vfinal.

31 Esta contracción se acompaña de una fuerte disminución en la inversión en maquinara y equipo en la industria de $-28 \%$, lo que indica que la crisis global tiende a coincidir con una nueva crisis subcíclica de los dispositivos de memoria DRAM y Nand, y de un aumento de $4 \%$ en la demanda de insumos para semiconductores, lo que está determinado por la demanda del mismo tipo de insumos por parte de la industria de producción de fotoceldas solares (Semiconductor International, 12/03/2009).

32 Desglosada de lasiguiente manera: equipodecomputación-15\%; equipode telecomunicaciones $-9.2 \%$; servicios de base electrónica-informática $-1.7 \%$; el gasto en software es el único rubro que seguirá creciendo a razón de $0.3 \%$ (EDT, 31/03/2009 y Semiconductor International, $12 / 03 / 2009)$. 
Finalmente, las principales empresas de todas las ramas tienen coeficientes positivos de efectivo sobre deuda al final de 2007, en 2008 y 2009-1 (entre US\$ 8 mmd y 45 mmd), con excepción de la electrónica de consumo (que presenta coeficientes negativos entre -20 mmd y -35 mmd en 2008 y 2009-1, respectivamente); en todos los casos, el coeficiente es superior al que prevaleció durante la crisis de 2001-2002 (OCDE, 2009), así que la restricción del crédito no ha afectado de manera importante a la industria, ya que cuenta con un considerable flujo de ingresos y el efecto de la crisis en general ha sido moderado, no obstante la presencia de aspectos preocupantes como el que no haya disminuido el uso de la capacidad instalada ante el aumento de los inventarios en la industria de semiconductores, que podría originar una fuerte contracción de la producción y, por consiguiente, una recuperación ${ }^{33}$.

La recuperación de la industria podría comenzar a partir de la segunda mitad de 2009, gracias a la confluencia de diversos elementos como el efecto de los paquetes de estímulos económicos de los diversos países, que mundialmente suman US $\$ 2$ billones, las tasas de interés excesivamente bajas, así como la fuerte contracción de la inversión en maquinaria y equipo de la industria de semiconductores durante 2008 y 2009, que traerá consigo la necesidad de un fuerte reequipamiento (Electronic News, 10 de abril de 2009) ${ }^{34}$.

\section{La industria de servicios de telecomunicaciones}

Las actividades de servicios del SE-I han sufrido una contracción aun menor que las industriales; la mayor caída de los ingresos se observa en la industria de internet, seguida de la del software y los servicios computacionales; la ISTC sufrió reducciones en sus ingresos en 2008-1 pero, a diferencia del resto de las actividades, se recuperó durante el resto del año y el primer trimestre de 2009 (véase gráfica 4).

$\mathrm{Al}$ igual que las actividades industriales, las de servicios sufren un efecto aun menor en la inversión en I\&D que se mantiene en crecimiento durante prácticamente todo 2008 y 2009-1 (la inversión de la industria del software apenas disminuye en 2008-3), aun cuando el coeficiente de efectivo de la deuda de las 10 principales empresas es negativo en 2007 tanto en la industria de internet como en la ISTC: -350 mmd a finales de 2007, en 2008 y 2009-1 (OCDE, 2009).

33 Lo anterior coincide con un incremento en la inversión de capital en la industria en 2007 y 2008, por países como China y Taiwán con las tasas de crecimiento más elevadas en 2007 ( $50 \%$ y $40 \%$, respectivamente) y se espera que el Sudeste asiático tome el primer lugar en 2008, con un incremento de alrededor de 30\%, seguido de Europa y Medio Oriente (incluido Israel) con alrededor de 16\% [Semiconductor International, 01/01/2008].

34 Un elemento adicional que podría indicar un repunte, es el hecho de que tradicionalmente la demanda por productos electrónicos es mayor en la segunda mitad del año en relación con la primera, a lo que se agrega el aumento observado en la demanda de productos electrónicos y semiconductores que ha seguido a las sucesivas recesiones en los últimos 30 años (Electronic News, 10/04/2009). 
Gráfica 4.

Crecimiento trimestral de la inversión I-D de las

10 principales empresas en servicios del SE-I

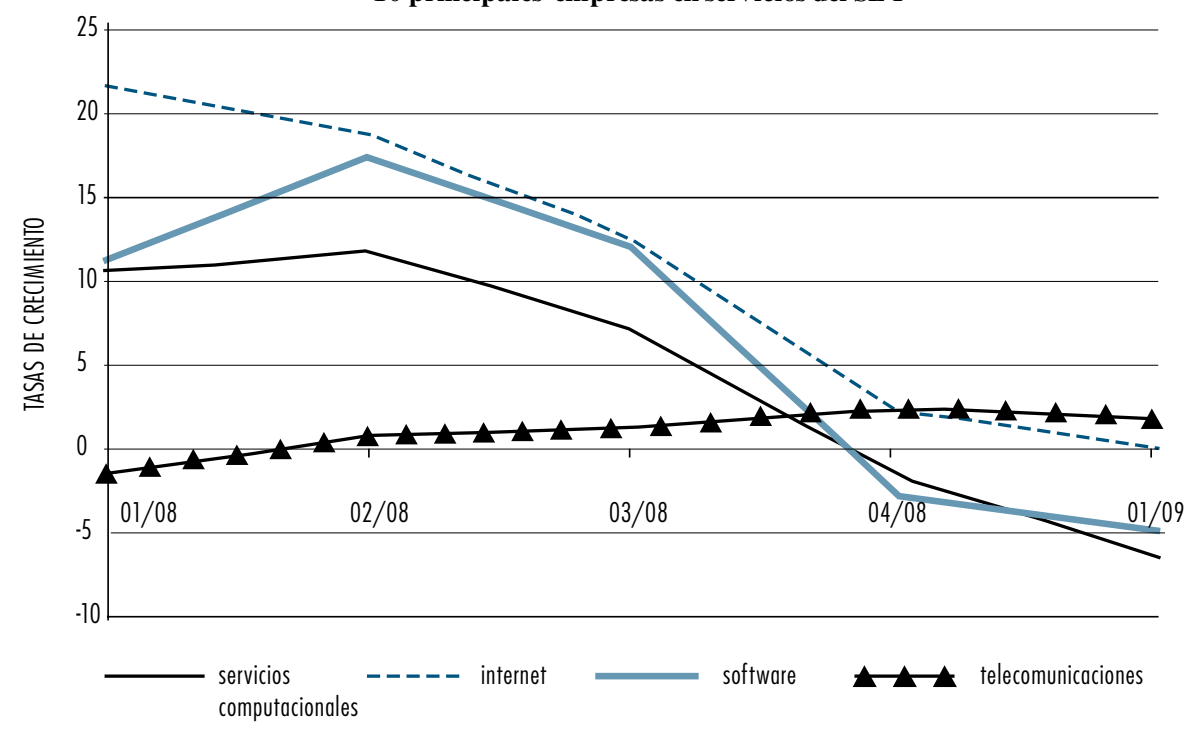

Fuente: elaboración propia a partir de los datos que presenta la OCDE en el documento: The im pact of the crisis on ICTs and their role in the recovery, 28 de julio de 2009. dsti/iccp/ie(2009) V/final.

Específicamente la ISTC, al igual que el conjunto del SE-I, luego de la crisis de 20012002 sufre un proceso de reestructuración con características específicas ${ }^{35}$, entre las que destaca por su importancia en el desarrollo ulterior a la crisis actual de la industria -como se verá más adelante-, la tendencia a un nuevo despliegue espacial, en el cual los EEUU y Europa tienden a perder peso en los ingresos totales de la industria, mientras la región emergente de mayor importancia por el incremento de su peso en los ingresos totales es Asia-Pacífico, seguida de América Latina y Medio Oriente-África (en esta última tiene lugar el crecimiento más dinámico de los ingresos) (véase Ordóñez y Correa, 2009), como se muestra en el cuadro 2.

35 Las características de la reestructuración de la industria son: 1) su gran intensidad en capital fijo infraestructural y los consiguientes requerimientos de grandes inversiones que anticipen el ciclo expansivo esperado; 2) la revolución tecnológica de la industria, consistente en un desarrollo sin precedentes de las redes de interconexión e internet; 3) la sustitución del equipo de tecnología tradicional (legacy equipment) por el equipo basado en internet (IP equipment) por parte de las empresas; 4) una nueva tendencia a la integración horizontal de servicios por parte de los nuevos operadores originalmente asentados en diversas ramas y que tienden a converger en una nueva industria de servicios de telecomunicaciones integradora (servicios agregados de triple y cuádruple play); y 5) el referido despliegue espacial (véanse Ordóñez y Bouchaín, 2008; Ordóñez y Correa, 2009). 
Cuadro 2.

Ingresos de la industria global de servicios de telecomunicaciones por región

\begin{tabular}{|l|r|r|r|r|r|r|r|}
\hline \multirow{2}{*}{ REGIÓN } & \multicolumn{7}{|c|}{ (PORCENTAJE) } \\
\cline { 2 - 8 } & 2000 & 2001 & 2002 & 2003 & 2004 & 2005 & 2006 \\
\hline Estados Unidos & 37.3 & 35.8 & 34.3 & 33 & 32.1 & 31.2 & 30.7 \\
Europa & 36.7 & 34.7 & 35.2 & 35.3 & 35.2 & 34.8 & 34 \\
Canadá & 2.3 & 2 & 1.9 & 1.8 & 1.7 & 1.5 & 1.4 \\
Asia/Pacífico & 16.6 & 19.9 & 21 & 22.1 & 22.5 & 23 & 23.8 \\
Latinoamérica & 5.2 & 5.6 & 5.7 & 5.8 & 6.1 & 6.7 & 7.1 \\
Medio Oriente/África & 1.8 & 1.8 & 1.9 & 2.1 & 2.3 & 2.8 & 3.1 \\
\hline Total & 100 & 100 & 100 & 100 & 100 & 100 & 100 \\
\hline
\end{tabular}

Fuente: TIA's (2007)

En 2008, el gasto de capital continuó creciendo en 8.3\% (de US \$131 mmd en 2007 a 142 mmd), aunque en 2009 se contraerá en -7\%; Norteamérica y Europa occidental serán las regiones más afectadas (gráfica 5), por lo que el proceso de redespliegue espacial seguirá acentuándose en favor de las regiones emergentes, particularmente Asia-Pacífico, con la consiguiente tendencia al desplazamiento del eje dinámico de la industria hacia esas regiones. Por su parte, el comercio de servicios de telecomunicaciones de los países líderes no fue afectado por la crisis hasta el segundo trimestre de 2008, e incluso se verificó un ligero aumento de las exportaciones y el saldo comercial en los

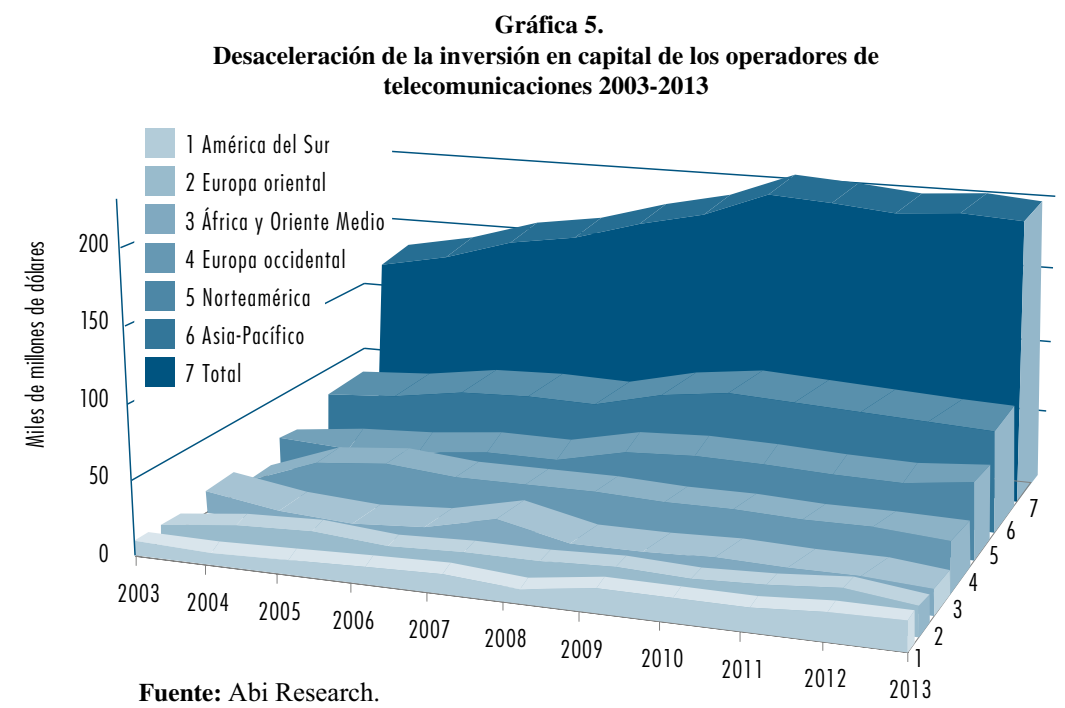


primeros trimestres de ese año (véase gráfica 6). En cambio, el comercio de servicios de telecomunicaciones de los países emergentes sí se vio afectado a partir del cuarto trimestre de 2007, observándose una tendencia a la contracción de las exportaciones mayor que la de las importaciones, con la consiguiente reducción del saldo comercial, como lo muestra la gráfica 7 .

Gráfica 6.

Países líderes*: comercio de telecomunicaciones,

2007-1 a 2008-2 (miles de millones de dólares)

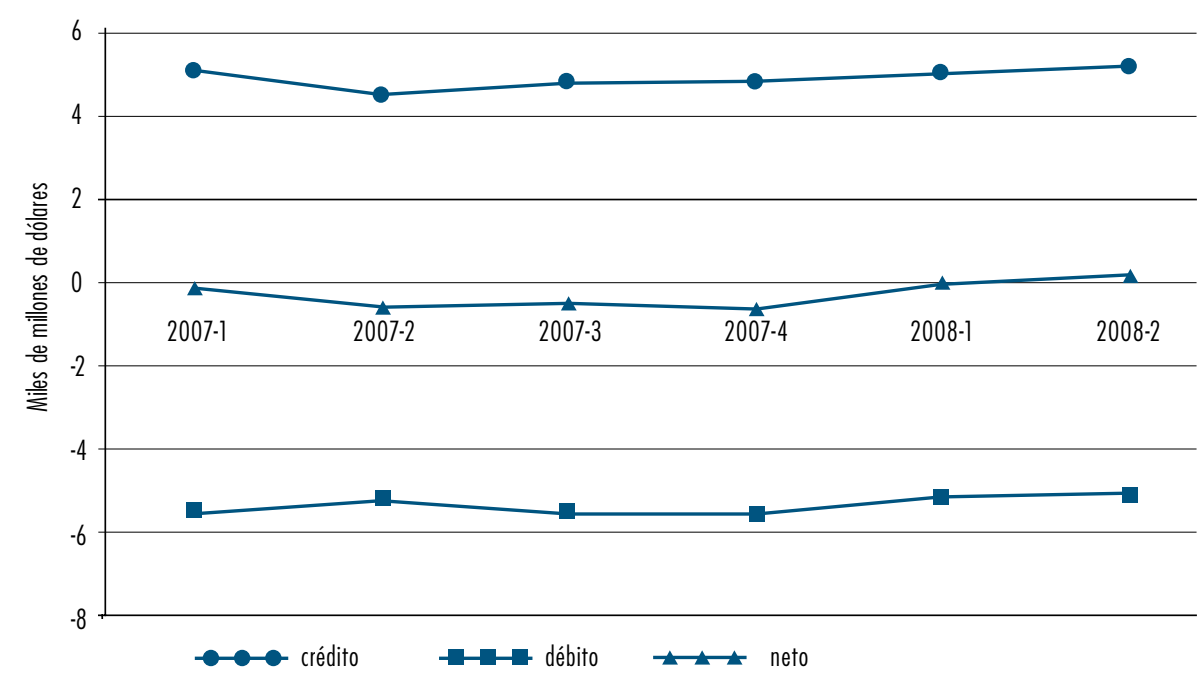

Fuente: FMI

*Países líderes: Estados Unidos, Bélgica, Portugal, Noruega, Suecia, España, Italia y Alemania.

En el caso de México, la tendencia a la disminución de las exportaciones es un fenómeno que se ha experimentado desde 2006 (IMF-BOP) y que tiende a profundizarse en el último trimestre de 2007 y el primero de 2008, como resultado de la falta de competitividad de la ISTC en el país, situación que se recrudece con el despliegue mundial de la crisis. 
Gráfica 7.

Comercio de telecomunicaciones

México y países emergentes 2007-1 a 2008-1

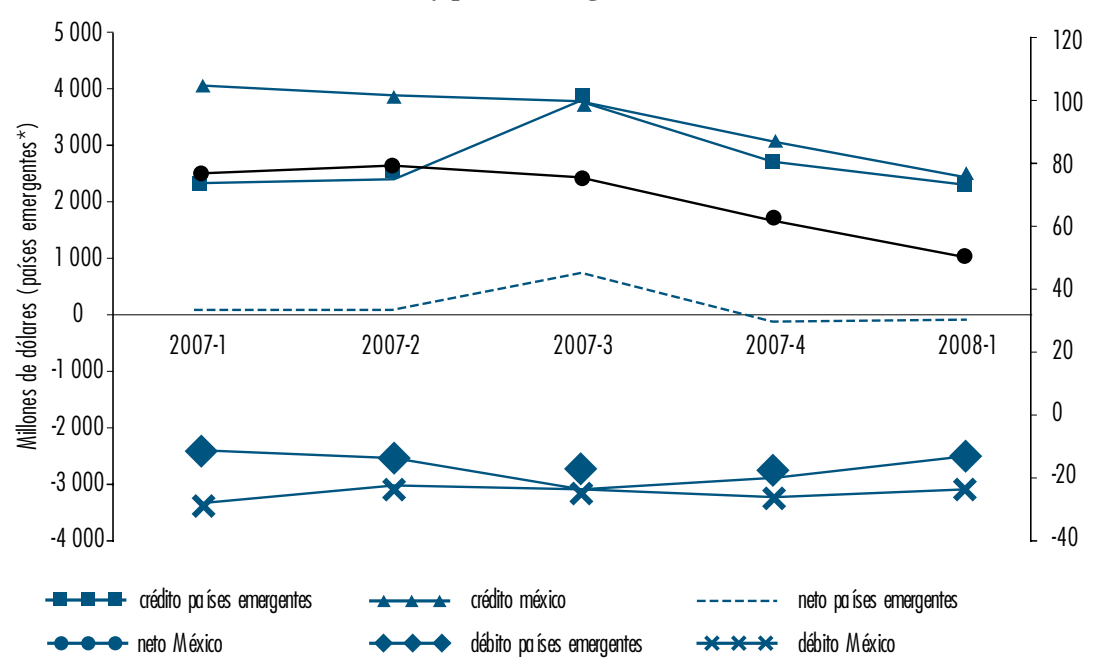

*Países que se refieren al grupo dos: Tonga, Filipinas, Rumania, Marruecos,

Croacia, Turquía, Guatemala, Brasil, República Checa, Malasia, Irlanda, República Eslovaquia,

Austria, Colombia, Líbano, Sudáfrica, Argentina, Hungría, Rusia, Grecia, Israel, Finlandia, Corea.

\section{El sector electrónico-informático en México: ¿elemento dinámico de la recuperación?}

\section{Antecedentes}

El SE-I nacional constituye alrededor de $6 \%$ del valor agregado por las empresas privadas en 2000 y está compuesto por tres actividades fundamentales: 1) una industria electrónica que ha pasado a constituir la principal actividad manufacturero-exportadora, además de estar en proceso de consolidación como actividad dinamizadora e integradora del crecimiento económico en los noventa, si se considera el componente importado de la economía; 2) una industria de servicios de telecomunicaciones con cierta ventaja tecnológica pero escasa penetración de los servicios -en relación con países de desarrollo similar-, cuyos precios se encuentran entre los más elevados del mundo; y 3) una industria del software de incipiente desarrollo (Ordóñez, 2006) ${ }^{36}$. A continuación, se describen brevemente las principales características del desarrollo reciente de las primeras dos actividades, que son las más relevantes.

36 Otra actividad importante de integración es la industria de servicios de televisión y de contenido en general. 


\section{La industria electrónica}

El desarrollo reciente de la industria electrónica en México tiene lugar en la década de 1990, en el contexto de la apertura comercial del país y la firma del Tratado de Libre Comercio de América del Norte, marco en el cual se constituye como una industria básicamente de ensamble y manufactura, orientada a la exportación y conformada por dos segmentos industriales de origen y régimen regulatorio diferentes: el segmento de maquila y el segmento reconvertido de la sustitución de importaciones (Dabat y Ordóñez, 2009).

La industria se forma a partir de un intenso proceso de desplazamiento hacia México de partes sucesivas de las cadenas de producción globales -que se traduce en un rápido incremento de la inversión extranjera en la industria-, para hacer frente a la competencia global por parte de las principales empresas OEM, que atraen a sus contratistas manufactureros internacionales, así como a algunos proveedores de segundo círculo de ambos, lo que da como resultado una industria formada básicamente de productos finales del complejo de computadoras (computadoras y equipo periférico), electrónica de consumo (televisores), equipo de telecomunicaciones (telefonía alámbrica e inalámbrica) y, secundariamente, de componentes y semiconductores.

Durante el periodo de expansión de la década de 1990, la industria crece intensamente a partir de una modalidad de desarrollo basada en la fabricación de productos de poco contenido en valor agregado, baja variedad de componentes y producidos en grandes series, en particular de los sectores de equipo de cómputo y oficina y equipo de telecomunicaciones, lo cual requiere actividades de I\&D mínimas concentradas en estos sectores productivos ${ }^{37}$.

Sin embargo, esta modalidad de desarrollo muestra signos de agotamiento a finales de los noventa (es decir, antes de la crisis mundial de 2001-2002), que se manifiestan en el descenso del flujo de inversión extranjera, la desaceleración de los incrementos de productividad del trabajo y de la competitividad industrial internacional (costo laboral unitario medido en dólares), y los primeros casos de empresas maquiladoras que se retiran del país para establecerse en China (Dabat y Ordóñez, 2009).

37 La caída en el gasto en I\&D se origina en el cambio en la modalidad de desarrollo de la industria hacia la primera mitad de los noventa, en el que las empresas OEM abandonan el programa de formación de proveedores locales seguido desde 1985 — que requería actividades de I\&D-, en favor de la radicación de sus contratistas manufactureros internacionales en el país para la fabricación del tipo de productos señalado en el texto (Ordóñez, Dabat y Rivera, 2005). 
La recuperación de la industria electrónica en México, iniciada en 2004, se basa en una serie de importantes cambios de la modalidad anterior de desarrollo, cuyo origen -como en la etapa precedente de los noventa- no responde a factores internos de política pública, sino a la lógica de la reestructuración del SE-I mundial, particularmente del estadounidense. La industria encuentra una salida espontánea a su crisis, centrada en un relativamente rápido proceso de reconversión de su modalidad de desarrollo en torno de los siguientes cuatro lineamientos principales, que explican el incremento en la inversión en I\&D y su reorientación hacia los componentes y semiconductores y los instrumentos de precisión, hacia finales de la década de 1990 e inicio de la de $2000^{38}:$ 1) ascenso industrial en las cadenas globales de valor hacia actividades más intensivas en diseño y procesos de manufactura que implican más conocimiento, con mayor valor agregado y que crean productos que requieren una mayor variedad de componentes y producción de series más reducidas (medianas series $)^{39}$; 2) integración de la industria en la nueva modalidad de la división interindustrial del trabajo, por medio de la relocalización de las empresas OEM de operaciones de diseño en el país o la incorporación de empresas subcontratistas locales en el proceso; 3) reorientación de la producción hacia sectores o subsectores emergentes o de alto dinamismo, como los instrumentos de precisión, la electrónica de consumo de nuevo tipo, la electrónica automotriz o la aeroespacial, lo cual, en conjunto con los puntos 1 y 2 , proporcionará a la industria del software una vía de evolución y encadenamiento con la industria electrónica; y 4) redistribución geográfica de las exportaciones en detrimento del mercado estadounidense y a favor de China, Japón y Europa, lo que implica el inicio de la integración internacional de la industria por medio del mercado en la emergencia de China y Asia oriental posterior a la crisis mundial de 2001-2002 (Dabat y Ordóñez, 2009).

\section{La industria de servicios de telecomunicaciones}

El desarrollo reciente de la industria de servicios de telecomunicaciones ha estado determinado por los cambios en las condiciones de la competencia interna, resultado de la privatización de Telmex (la rama de telefonía constituye alrededor de $90 \%$ de la

38 Presumiblemente, la inversión en I\&D en la industria electrónica aumenta con la recuperación, a partir de 2004.

39 Este proceso particular que tiene lugar en la industria electrónica como medio de salida de la crisis, ya había sido estudiado para la industria en su conjunto y como aspecto evolutivo de la industria de maquila en el concepto de maquila de tercera generación, formulado en el periodo de expansión de los años noventa, por Carrillo y Hualde, 1997. 
producción bruta de la industria), que trajo consigo la modernización de la infraestructura en telecomunicaciones, la apertura a la competencia de la provisión de la demanda de la empresa y la apertura del mercado de larga distancia, primero, y del de telefonía local, después. La modernización infraestructural ha implicado efectos multiplicadores sobre la industria: aumento sustancial de las líneas telefónicas, introducción de cables de fibra óptica, mayor uso de satélites, construcción de nuevos centros de interconexión digital y estaciones de relevo, y, más recientemente, la introducción de redes inalámbricas, lo cual ha provocado el aumento en la demanda de equipos de telecomunicaciones (UNIDO, 1994; Ruelas, 1995; USDC, 2002; Escobar de Medécigo, 1999).

La gran concentración de la producción en la telefonía, particularmente en la telefonía fija (en 2003, 0.04 de las empresas concentraban 52.4\% de la producción industrial y $58.2 \%$ de los activos fijos), sustentada en el control sobre la red terminal o última milla por parte del operador monopólico, se traduce en una modalidad rentista de crecimiento que incide sobre el conjunto de la industria con las siguientes características: 1) la existencia de un sobreprecio del servicio telefónico, tanto fijo como móvil, que constituye el fundamento de una sobreganancia de la rama, que aunada a la sobrevaluación del tipo de cambio previa a la crisis global ${ }^{40}$ ha financiado la vertiginosa expansión internacional del operador monopólico de telefonía fija y móvil hacia Latinoamérica, es decir, las empresas Telmex-Telcel (Ordóñez y Bouchaín, 2007). En tan sólo 11 años de expansión ${ }^{41}$, el operador monopólico se coloca como uno de los cinco principales operadores de telefonía móvil en el mundo por número de suscriptores, incrementa la proporción de ingresos externos en los ingresos totales de $10 \%$ en 1999 a 59\% en 2007 y alcanza una participación en el mercado latinoamericano que se acerca a un $50 \%{ }^{42} ; 2$ ) lo anterior se expresa en una baja tasa de penetración de la telefonía fija (México se encuentra en un nivel internacional medio-bajo, con penetración menor a 20 líneas fijas por habitante), así como en telefonía móvil; y 3)

40 En el periodo de expansión internacional de Telmex-América-Móvil de 1997 a 2005, el tipo de cambio tiene una sobrevaluación promedio de 4.26 por ciento.

41 A partir de 1997, la empresa comienza su estrategia de expansión en América Latina, con la compra de Telecomunicaciones de Guatemala (Telgua), ante las dificultades para expandirse en los EEUU, que fue su primer objetivo. Buscó poner pie en Brasil y Colombia para luego expandirse a Argentina, a otros países centroamericanos (El Salvador, Nicaragua y Honduras) y más recientemente a Chile, Paraguay y Perú. Se ha expandido mediante la adquisición de otras empresas telefónicas, empresas de cable (particularmente en Brasil) y empresas de servicios basados en internet, como transmisión de datos y acceso a internet en Argentina. Véase Mariscal y Rivera, 2005.

42 Véanse Mariscal y Rivera, 2005; OCDE, 2005 y Base de datos financieros de Economática, 2008 . 
debido al amplio predominio del acceso a internet vía telefónica (aproximadamente $81 \%$ de los suscriptores en 2006), existe un sobreprecio en el acceso a internet que se traduce en la baja tasa de penetración (19\%), la tardía disminución de la conexión dial up y del crecimiento de la conexión DSL (aun cuando en 2006 el crecimiento fue importante), $\mathrm{y}$, consecuentemente, baja cobertura tanto total como por habitante del ancho de banda internacional y su trayectoria declinante y, por ende, el escaso desarrollo del acceso de banda ancha (Ordóñez y Correa, 2009).

Por otra parte, los ingresos de la industria han crecido sin interrupción luego de la crisis de 1994-1995: 12.7\% anual en el periodo 2001-2005 (con lo que superan 11.7\% de crecimiento de los ingresos de la industria mundial, y el 6.4\% de los EEUU), mientras que el coeficiente de inversión a ingresos ha tendido a disminuir a partir de 2001 (año en que la inversión alcanza su monto máximo) (véase gráfica 8), por lo que la industria cuenta con un considerable flujo precedente de ingresos para afrontar la crisis, ampliado por la baja tasa de inversión, en relación con la industria mundial.

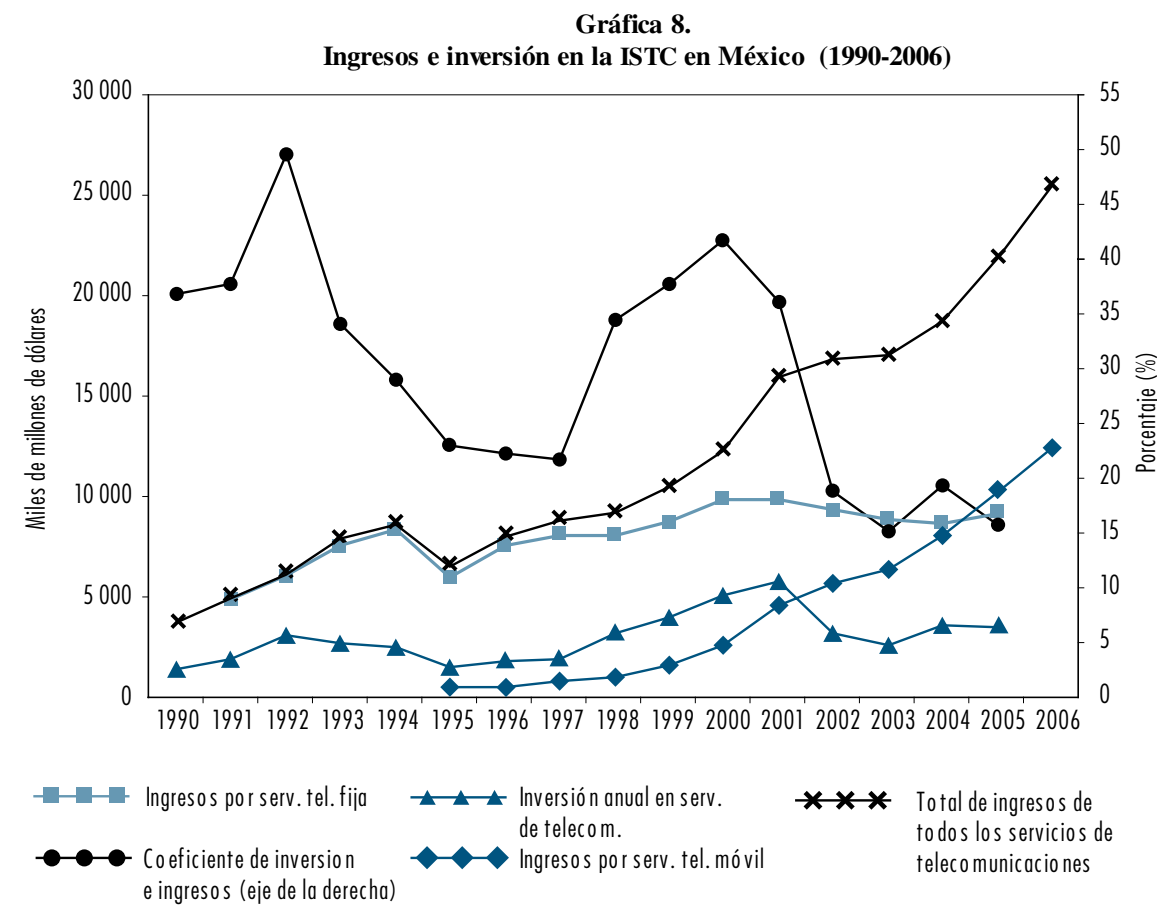

Fuente: FMI

*Países que se refieren al grupo dos: Tonga, Filipinas, Rumania, Marruecos,

Croacia, Turquía, Guatemala, Brasil, República Checa, Malasia, Irlanda, Eslovaquia,

Austria, Colombia, Líbano, Sudáfrica, Argentina, Hungría, Rusia, Grecia, Israel, Finlandia, Corea. 


\section{¿Elemento dinámico en la recuperación?}

Si se toma a los EEUU como base del desenvolvimiento de las exportaciones de la industria electrónica durante el periodo de la crisis global, el efecto de ésta hasta el cuarto trimestre de 2008 parece haber sido mínimo para México al igual que para China, cuya dinámica de crecimiento previo había sido mayor, como lo muestra la gráfica 9.

Gráfica 9.

Exportaciones electrónicas de México y China a EEUU 2006-1

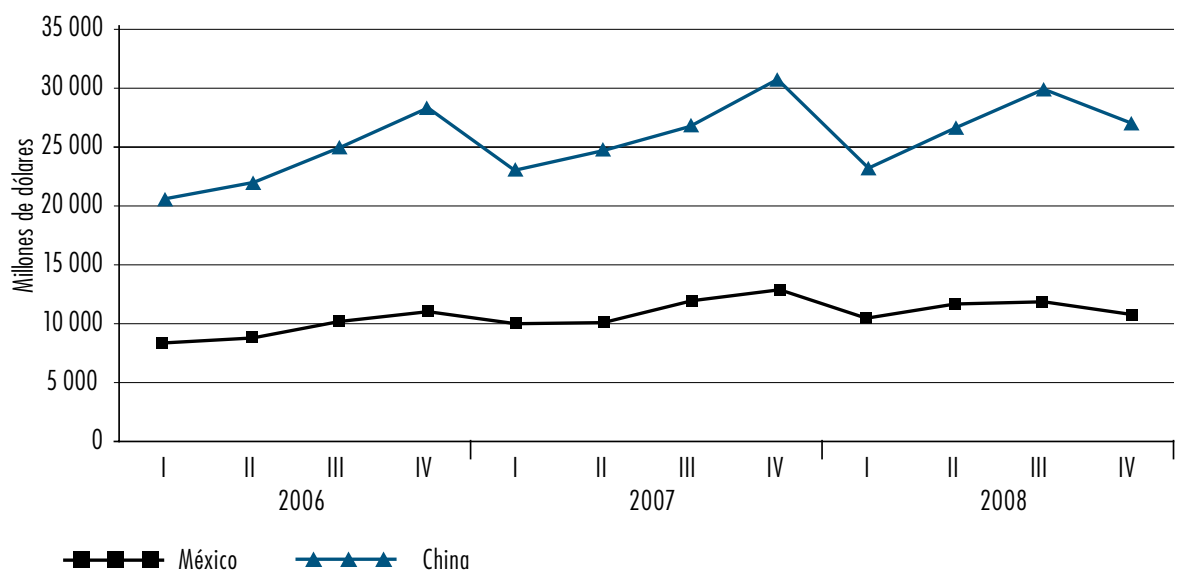

Fuente: http://www.census.gov

Al considerar estos datos es necesario tener presente la redistribución geográfica de las exportaciones en detrimento de los EEUU y en favor de China, la Unión Europea-25 y Japón, como condicionante de la salida de la crisis de 2001-2002. Desde esa perspectiva, el desempeño de las exportaciones a los EEUU explica alrededor de $61 \%$ de las exportaciones de la industria (Dabat y Ordóñez, 2009), pero es probable que el proceso de redistribución geográfica se haya acentuado durante la crisis global y que China haya aumentado su participación al continuar creciendo a un ritmo de alrededor de 6\%, por lo que el efecto sobre las exportaciones totales de la industria podría ser menor al mostrado en la gráfica 9 .

El desempeño sectorial de las exportaciones a los EEUU muestra como sectores menos afectados a los de electrónica de consumo, equipo de telecomunicaciones e instrumentos de precisión, mientras que los más afectados han sido computadores y equipo de oficina y componentes y semiconductores (véase gráfica 10). 
Gráfica 10

Exportaciones electrónicas de México hacia EEUU 2006-1 a 2008-4

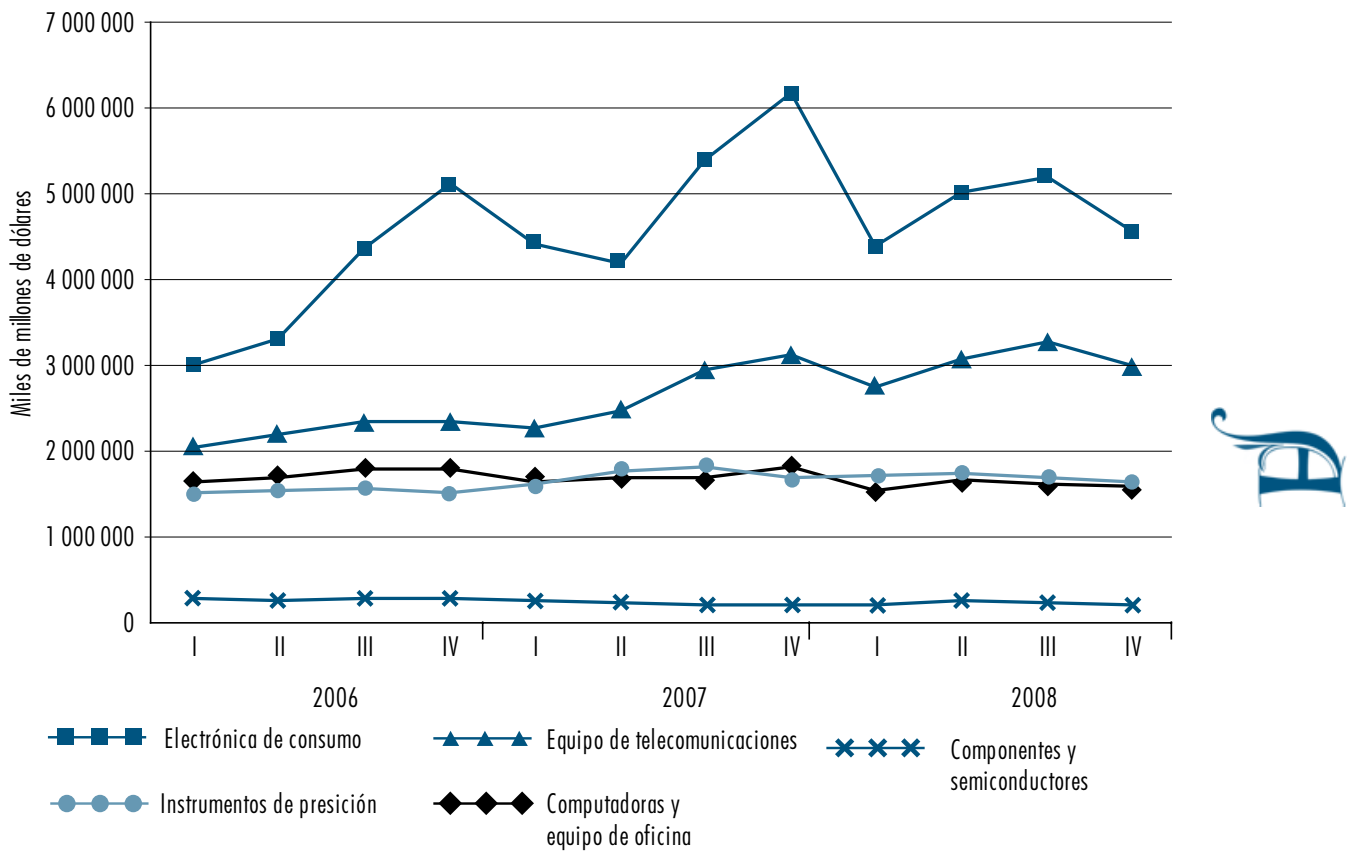

Fuente: http://www.census.gov

Como se ha visto, es muy probable que la crisis acentúe los procesos de relocalización-subcontratación, particularmente en la IE de los EEUU, lo que tenderá a reforzar el perfil de especialización de México en la exportación de productos medianamente intensivos en conocimiento, que incorporan una mayor variedad de componentes y que son producidos en series medianas.

Por su parte, la ISTC ha sido de las más dinámicas de la producción del país (gráfica 11) ${ }^{43}$; además, el volumen de actividad incluso aumenta durante 2007 y los tres primeros trimestres de 2008, por lo que el efecto de la crisis es bastante más moderado que en la ISTC mundial.

43 ITEL es un indicador de volumen de actividad de la industria, no de su valor reflejado en producción o ingresos, que incluye: 1) líneas fijas en servicio (alámbricas e inalámbricas), 2) tráfico en minutos facturados en telefonía móvil, 3) minutos facturados de larga distancia, 4) número de suscriptores a la televisión restringida (cable, satélite, microondas), 5) usuarios de radiolocalización de personas y flotillas, y 6) provisión de capacidad satelital (megahertz) para el suministro de servicios satelitales (Cofetel). 
Gráfica 11.

ITEL vs PIB: variación porcentual anual

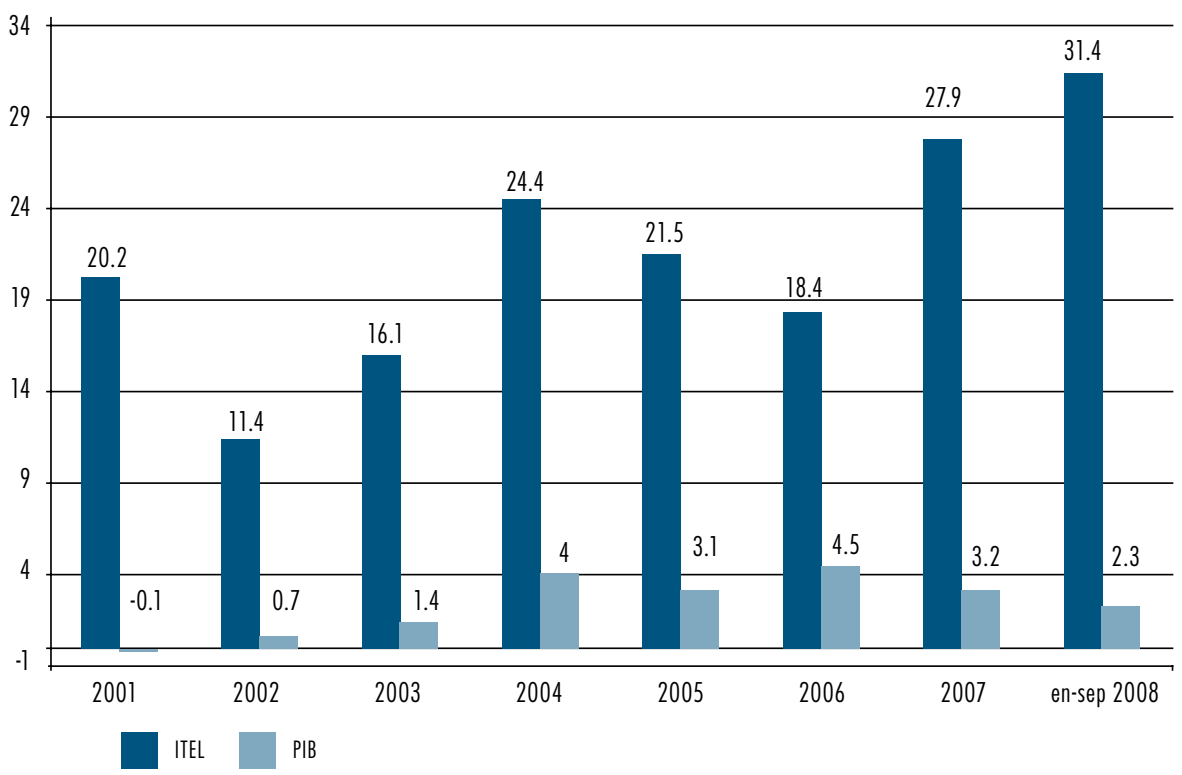

Fuente: elaboración propia con datos de Carmen DeNavas-Walt, Bernadette D. Proctor, Jessica C. Smith, 2007 y U.S. Census Bureau, 2008: 13.

Adicionalmente, las actividades que han reducido su dinámica lo han hecho por factores ajenos a la crisis, como a continuación se explica: $a$ ) el paging, debido a la tendencia a la sustitución de estos servicios por los que proporcionan actividades como la telefonía móvil y los servicios satelitales; $b$ ) la telefonía fija, por la tendencia (de canibalismo) a su sustitución por la telefonía móvil; $c$ ) la televisión por microondas, a causa de la competencia de la televisión por cable y satelital, las cuales no reducen su actividad; $d$ ) la larga distancia entrante, ocasionada muy probablemente por la disminución del tráfico originado por los migrantes e íntimamente ligado al descenso de las remesas; y $e$ ) internet, cuyo crecimiento trimestral medio fue de sólo $3.5 \%$ en 2007 y la primera mitad de 2008 (con tres trimestres negativos) ${ }^{44}$ (INEGI-CNBIE), debido a la limitación determinada por el sobreprecio del acceso telefónico.

Finalmente, la disminución de las exportaciones de servicios de telecomunicaciones (reducción del tráfico entrante), observada en la gráfica 7, es una tendencia que inicia en 2000 (IMF-BOP) y que la crisis sólo acentúa, tendencia determinada por la baja competitividad de la industria, íntimamente relacionada con su modalidad de crecimiento imperante.

44 El crecimiento trimestral de los ingresos de internet en el periodo es como sigue: $-1.04 \%$, $-0.81 \%, 39-01 \%,-24.49 \%, 0.23 \%$ y $8.32 \%$ (INEGI-CN-BIE). 
Por consiguiente, la crisis ha afectado poco a las actividades principales del SE-I en México, gracias a que antes tuvieron un considerable flujo de ingresos que las hace estar bien posicionadas para enfrentarla y erigirse en un elemento dinámico de la recuperación del país. Sin embargo, es muy probable que el buen posicionamiento y su potencial papel dinámico inhiban las reformas necesarias en la modalidad de crecimiento de ambas actividades que permitan al SE-I nacional tener un verdadero poder de arrastre no sólo sobre el elemento importado sino sobre el conjunto de la economía interna, además de contribuir a la formación de una infraestructura competitiva, consistente y dinámica para la integración internacional y el desarrollo interno de procesos de conocimiento. Es decir, previsiblemente, el buen posicionamiento para la recuperación en las condiciones actuales del país, actuará en contra de la necesaria reorientación de la modalidad de desarrollo del SE-I nacional que posibilite la transmisión al conjunto de la economía de toda su potencialidad dinámica y competitiva.

\section{Consideraciones finales}

La crisis financiera y productiva global tiene su epicentro en el sector inmobiliario de los EEUU y otros países, sobre éste se constituye un enorme y complejo circuito financiero que incluye a diversos agentes. Este circuito se encarga de propiciar una dinámica frenética de atracción y canalización de capital ficticio a partir de la difusión del riesgo asociado a las securities y los instrumentos derivados respaldados en hipotecas entre los agentes involucrados en el circuito, que conduce a la formación de una enorme burbuja financiera, cuyo estallido provoca el inicio de la crisis en su etapa financiera exclusivamente, lo que luego se traduce en la virtual paralización del crédito mundial que agrega a la crisis financiera su dimensión productiva.

Al constituir el eje dinámico del crecimiento mundial desde la década de 1990, generar ingresos en aumento desde su punto más bajo a inicios de 2002 y, consecuentemente, tener un bajo nivel de endeudamiento, el SE-I mundial ha sufrido un efecto moderado de la crisis y se encuentra bien posicionado para ser de nuevo el eje dinámico de la recuperación; China y Asia oriental, además de otras regiones y países emergentes, desempeñarán un papel protagónico. En este proceso, cobrarán importancia las tendencias a la producción, gestión y uso social racionalizado de las tecnologías electrónico-informáticas, que al mismo tiempo impliquen un ahorro de costes en el corto y mediano plazos para las empresas y gobiernos en lo individual, en donde destacan los siguientes aspectos: 1) la cooperación entre computadoras y el desarrollo de las redes de interconexión y de internet en su dimensión integradora de la interacción y operación de dispositivos, así como de soporte de nuevos servicios que adquieren una base tecnológica digital;2) la tendencia a la sustitu- 
ción del software propietario por software libre y de fuente abierta y la distribución de software como servicio; y 3) la relocalización-subcontratación de actividades de investigación y desarrollo, concepción y diseño o manufactureras, y servicios de mayor valor agregado, así como de las actividades tradicionales, de bajo contenido en conocimiento y valor agregado.

Sin embargo, la salida de la crisis requiere superar la etapa de la "autorregulación privada" en la que se sustenta el neoliberalismo -como modalidad de la globalización y del capitalismo del conocimiento-, dominada por el capital financiero, para dar paso a una nueva etapa dominada por el capital productivo, que necesariamente se acompañará de intensas reformas político-institucionales orientadas al fortalecimiento de la capacidad del Estado frente al mercado en el proceso de gobernancia económica, así como una nueva incidencia de organizaciones sociales emergentes.

Frente a esta perspectiva, México se encuentra en una situación político-institucional de grave rezago, al sustentar su desarrollo reciente basado en las exportaciones manufactureras en los principios de la "autorregulación privada", que aunque han permitido el desarrollo de un SE-I nacional importante, carece de capacidad dinamizadora e integradora del crecimiento de la economía interna (capacidad desarrollada en relación con el elemento importado de la economía básicamente), además de constituir un lastre para el desarrollo de una infraestructura en telecomunicaciones competitiva, consistente y dinámica para la integración internacional y el desarrollo interno de procesos de conocimiento.

Sin embargo, la crisis financiera y productiva global no ha afectado mucho al SE-I nacional, y gracias al considerable flujo de ingresos que éste generó antes de la crisis, se encuentra en condiciones de desempeñar un papel dinámico en la recuperación, a partir de una integración internacional más acentuada en los procesos de relocalización-subcontratación de procesos medianamente intensivos en conocimiento, básicamente desde los EEUU, en la industria electrónica, así como la continuación del crecimiento acelerado de la industria de servicios de telecomunicaciones sobre bases rentistas.

Paradójicamente, constituir un elemento dinámico en la recuperación bajo estas condiciones, tenderá a bloquear las reformas necesarias en la modalidad de crecimiento del SE-I nacional, que le permitirían transmitir al conjunto de la economía toda su potencialidad dinamizadora e integradora del crecimiento, así como su capacidad competitiva infraestructural en los procesos internos e internacionales de conocimiento. Resolver este nudo histórico es uno de los grandes desafíos que enfrenta el futuro del país. 


\section{Bibliografía}

Aspe, Pedro, El camino mexicano de la transformación económica, México, FCE, 1993, pp. 133.

ADB Economics, The US Financial Crisis, Global Financial Turmoil, and Developing Asia: Is the Era of High Growth at an End?, Asian Development Bank, Working Paper núm. 139, diciembre de 2008.

Ashcraft, Adam B. y Til Schuermann, Understanding the Securitization of Subprime Mortgage Credit, Federal Reserve Bank of New York Staff, Reporte núm. 318, marzo de 2008. [http://www.newyorkfed.org/research/staff_reports/sr244.pdf].

Bajaj, Vikas, "US tries a trillion dollar keyfor locked lending", The New York Times, 20 de febrero de 2009 [http://www.nytimes. com/2009/02/20/business/20lend.html?_r=1.

Braun E., "SEMI's Forum considers slow growth, memory pains, design capability decline", Reed Business Information, $25 \mathrm{de}$ agosto de 2008.

Browning, Lynnley, "The subprime loan machine", The New York Times (versión electrónica), 23 de marzo de 2007: http://www.nytimes.com/2007/03/23/business/23speed.html

Carrillo, Jorge y Alfredo Hualde, "Maquiladoras de tercera generación. El caso de Delphi-General Motors", Comercio exterior, vol. 47, núm. 9, septiembre de 1997.

Cofetel, Índice del sector de telecomunicaciones, segundo trimestre de 2008.

Cooper, Charles, "Telcos said testing plan to offer PCs to businesses", CNET News, 3 de abril de 2009.

Coriat, Benjamin, Penser à l'envers, París, Christian Bourgios, 1991.

Dabat, Alejandro, "La crisis financiera de Estados Unidos y sus consecuencias internacionales", en Problemas del desarrollo. Revista latinoamericana de economía, vol. 40, núm. 157, abril-junio de 2009, pp. 40-74.

Dabat, Alejandro y Sergio Ordóñez, Revolución informática, nuevo ciclo industrial e industria electrónica en México, IIEC-UNAM, Juan Pablos, 2009.

Dash, Eric y Andrew Ross Sorkin, "Government seizes WaMu and sells some assets", The New York Times (versión electrónica), 25 de septiembre de 2008: http://www.nytimes. com/2008/09/26/business/26wamu.htm
Deffree, Suzanne, "July chip sales grow as $300 \mathrm{~mm}$ crossover continues", Electronic News, 2 de septiembre de 2008: http:// www.edn.com/article/CA6591971.html

, "Demand surge expected in second half, IC Insights says", Electronic News, 10 de abril de 2009: http://www.edn. com/article/CA6650773.html

Demyanyk, Yuliya y Otto van Hemert, "Understanding the subprime mortgage crisis", en The Review of Financial Studies, Universidad de Oxford, mayo de 2009, pp. 1-39. http://ssrn.com/abstract=1020396.

Economática Data Base 2008.

Engdahl, William, "Financial crisis: asset securitization. The last tango", http://www.globalresearch.ca/index. php? context $=$ va\&aid $=8032$

Escobar de Medécigo, Rebeca, "El cambio estructural de las telecomunicaciones y la inversión: el caso de México", Serie Reformas Económicas, núm. 17, 1999.

Foray, Dominique, L'économie de la connaissance, París, La Decóuverte Repères, 2000.

Garrou Philip, "IC Insights: Industry poised for rebound", Semiconductor international, 12 de marzo de 2009: http://www.semiconductor.net/article/208577-IC_Insights_Industry_Poised_for_Rebound.php

Gramsci, Antonio, "Noterelle sulla politica del Machiavelli", Quaderni del carcere, Quaderno 13: (1932-1934), Torino Einaudi, 1975.

$\mathrm{IAB}$, "Internet advertising revenue report", Interactive Advertising Bureau, mayo de 2008.

International Monetary Fund-Balance of Payment (IMF-BOP), consultado en http:// www.imfstatistics.org/imf

IMF-Global Financial Stability Report, 2007.

INEGI, Censos Económicos 1998 y 2003.

ITU, World Telecommunication / ICT Indicators Database. Cronological Time Series 19602006, Suiza, 2007.

ITU, International Telecomunication Union, Confronting the crisis. Its impact on the ICT industry, febrero 2009.

Kregel, Jan, "Changes in the US financial system and the subprime crisis", Working Papers núm. 530, The Levy Economics Institute of Bard College, Nueva York, abril de 2008, pp. 1-20. http://www.levy.org/vdoc. aspx?docid=105 
Lucas, Douglas J., L. Goodman y F. Fabozzi, "Collateralized debt obligations and credit risk transfer", Yale International Center For Finance, Working Paper núm. 07-06, pp. 1-14. [http://ssrn.com/abstract=997276].

Landey, Jim y Kenneth Lynch, "Telecommunications industry revenues 2006", Industry Analysis \& Technology Division Wireline Competition Bureau, agosto de 2008, www. fcc.gov/wcb/stats

Mariscal, Judith y Eugenio Rivera, Organización industrial y competencia en las telecomunicaciones en América latina: estrategias empresariales, Santiago de Chile, CEPAL (Serie de Desarrollo Productivo), 2005.

Marx, Karl, El capital, tomo III, México, Siglo XXI [1894], 1981.

Miller, Arnold, "Building a modern electronics industry", en Developing the Electronics Industry, Washington D. C., 1993.

Muci Facchín, Gustavo, Algunos aspectos legales de la titularización de créditos bancarios [http://www.deloitte.com/dtt/cda/ doc/content/La\%20Titularizaci\%F3n\%20 de $\% 20 \mathrm{Cr} \%$ E9ditos\%20Bancarios.pdf].

Naciones Unidas, Manual de estadísticas del comercio internacional de servicios, 2003.

OCDE, Communications Outlook, 2007 y 2005.

O'Brien, Kevin J., "Ericsson and Nokia Siemens are managing just fine", The New York Times, 13 de abril de 2009 [http:// www.nytimes.com/2009/04/13/technology/companies/13iht-network.ready.html].

Ordóñez, Sergio, "Nueva fase de desarrollo y capitalismo del conocimiento: elementos teóricos", Comercio exterior, vol. 52, núm. 1, enero de 2004.

,"El capitalismo del conocimiento. La nueva división internacional del trabajo y México", en Alejandro Dabat y José de Jesús Rodríguez (coords.), Globalización, conocimiento y desarrollo. La nueva economía global del conocimiento. Estructura y problemas, tomo I, IIEC, CRIM, FE, CCADET y Coordinación de HumanidadesUNAM, Miguel Ángel Porrúa (serie Las Ciencias Sociales), 2009, pp. 383-416.

Ordóñez, S. y R. Bouchaín, "Capitalismo del conocimiento, telecomunicaciones e integración internacional de México", en Comercio exterior, vol. 57, núm. 11, noviembre de 2007.

Ordóñez, S. y M, Correa, "México y Asia en los servicios de telecomunicaciones", $\mathrm{Co}$ mercio exterior, vol. 59, núm. 5 , mayo de 2009, pp. 348-369.
Ordóñez, S., A. Dabat y M. Á. Rivera, "La reestructuración del cluster de Guadalajara (México) y el nuevo aprendizaje tecnológico", en Problemas del desarrollo, vol. 36, núm. 143, octubre-diciembre de 2005, pp. 89-111.

Pérez, Carlota, "La otra globalización: los retos del colapso financiero", en Problemas del desarrollo, vol. 40, núm. 157, abril-junio de 2009, pp. 120-137.

Reinhart, Carmen M. y Kenneth Rogoff, "Is the 2007 US sub-prime financial crisis so different? An international historical comparison", Working Papers núm. 13 761, Cambridge, National Bureau Of Economic Research, enero de 2008, pp. 1-15. http:// www.nber.org/papers/w13761.

Ruelas, Ana Luz, México y Estados Unidos en la Revolución Mundial de las Telecomunicaciones, Austin, UAS-UNAM-UTA, 1995.

Semiconductor International, Equipment spending to decline $45.2 \%$ in 2009, Gartner says, 9 de abril de 2009.

Shirai, Sayuri, "The impact of the US subprime mortgage crisis on the world and East Asia: Through analyses of cross-border capital movements", en Munich Personal RePEc Archive, Working Paper núm. 14 722, abril de 2009, Universidad Keio, Japón, pp. 2-51: [http://mpra.ub.uni-muenchen.de/14722/]

TIA's, Telecommunications Market Review and Forecast, Telecommunications Industry Association, EEUU, 2007.

United Nations Industrial Development Organization (UNIDO), México, 1994.

United States Department of Commerce (USDC), Export IT, México, 2002.

Wellenius, Bjorn, "Electronics and the developing economies: introduction and overview", en Developing the Electronics Industry, Washington D. C., 1993.

Wikipedia, es.wikipedia.org

Whalen, R. Christopher. "The subprime crisis: cause, effect and consequences", Working Paper núm. 2008-PB-04, Networks Financial Institute de la Universidad Estatal de Indiana, marzo de 2008, pp. 1-17: http:// ssrn.com/abstract $=1113888$

World Economic Forum Annual Meeting Report, 2009, "ICT for economic growth: a dynamic ecosystem driving the global recovery" [http://www.weforum.org/pdf/ict/ ICT\%20for\%20Growth.pdf].

World Integrated Trade Solution (WITS), Database, 2008

Vol. 40, núm. 158, julio-septiembre / 2009 